\title{
En los albores del catastro parcelario territorial en España: los mapas topográficos de Granada y su área metropolitana (1819-1820)
}

\section{At the dawn of the territorial land registry of Spain: the topographic maps of Granada and its metropolitan area (1819-1820)}

\author{
Luis José García-Pulido
}

\section{INTRODUCCIÓN}

Este artículo aborda el análisis de la información catastral y la estadística parcelaria de Granada en la segunda década del siglo xix. Las fuentes del trabajo han estado constituidas por los mapas topográficos elaborados por Francisco Dalmau en 1819 y 1820, en especial el primero de ellos, junto a la información extraída de los apeos de rústica coetáneos, en particular el que hasta el momento arroja una visión más amplia y global del término municipal granadino, elaborado en 1817. Con este estudio particularizado del entorno de la capital granadina tras la Guerra de la Independencia se pone en relación una de las primeras cartografías parcelarias españolas y los datos catastrales ofrecidos por los documentos estadísticos conservados.

Como indican todas las cartelas de los mapas topográficos de 1820 y el primer cuaderno dirigido por Francisco Dalmau para expresar la riqueza territorial, industrial, y comercial de la Ciudad de Granada en el año 1818, la Estadística General de estos municipios fue realizada por orden de la Junta

\footnotetext{
${ }^{1}$ Universidad de Málaga, luis.garcia@uma.es. Laboratorio de Arqueología y Arquitectura de la Ciudad (LAAC, EEA, CSIC), luis.garcia@eea.csic.es.
} 
Principal de la Contribución General del Reino, creada por Martín de Garay y Perales Martínez de Villela y Franco, Ministro de Hacienda y Consejero de Estado. Tras la devastación producida por la invasión francesa, Fernando VII tuvo que reformar la Hacienda Pública y para ello era necesario conocer la riqueza que podía generarse en España. Debido a la necesidad de inventariar las distintas ramas productivas del país, Martín de Garay dispuso que se formase la Estadística del Reino por medio del Real Decreto de 30 de mayo de 1817 y de la Real Instrucción de 1 de junio de ese mismo año. Serían las Juntas de Contribución municipales las encargadas de elaborar las estadísticas parcelarias, eligiendo a los peritos para la confección de los apeos (Bringas Gutiérrez, 1994: 155-179; Bringas Gutiérrez, 2003: 143-157).

En los municipios del entorno granadino la dirección de este cometido habría recaído en Francisco Dalmau, quien dotó a la empresa de una importante componente cartográfica. El resultado fue excepcional, pues, aunque las capitales de provincia y los puertos habilitados quedaban excluidos de estos trabajos, en el caso de Granada se levantó un mapa de la ciudad y su término municipal, adelantado en su clase. Tal y como refiere su propia cartela se representaron los caminos, ríos, acequias, alquerías y pagos agrícolas, numerando las fincas y propiedades particulares para facilitar su localización en las extensas anotaciones marginales. Éstas contienen la clase y calidad de cada posesión, el propietario, arrendatario, número de árboles, superficie en fanegas y estadales o marjales y estadales, su valor, productos en especie o en reales de vellón y la renta que se pagaba, «todo lo cual no solo sirve de fundamento el más solido para saber la verdadera riqueza del país y formar la Estadística más exacta que se pueda desear, sino también para cuantas miras políticas y económicas puedan ofrecerse á un gobierno sabio é ilustrado».

Se pueden poner en relación estos trabajos de Francisco Dalmau con la experiencia que se tenía en otras regiones europeas, sobre todo en Francia, dado el contacto que pudo haber tenido con intelectuales e ingenieros militares de este país, como Académico que era y mediante la colaboración que prestó durante la ocupación de Granada entre 1810 y 1812. Desde 1807, Napoleón I encomendó a los ingenieros la tarea de obtener mapas catastrales precisos, prolongándose los trabajos desde 1808 hasta 1850, con una renovación total de los documentos cartográficos a partir de 1930. Es posible que este Catastro Francés o Napoleónico hubiese influido en la realización del mapa topográfico de 1819, donde se plasmaron los datos parcelarios y estadísticos recogidos el año previo por el equipo dirigido por Francisco Dalmau.

De este modo se convertiría en el precursor de los planos catastrales municipales de nuestro país, pues los trabajos más tempranos de esta índole elabora- 
dos en otras ciudades españolas fueron realizados tras el desarrollo de la Contribución Territorial en España en 1845 (Nadal, Muro y Urteaga, 2003: 37-60; Muro, Urteaga y Nadal, 2005: 7-39; Urteaga, 2011: 29-53). No sería hasta junio de 1859 cuando se aprobó la Ley de Medición del Territorio, que daría lugar a un proyecto de levantamiento catastral general de todo el país. La institución encargada de elaborar las cartografías parcelarias de las ciudades españolas fue la Comisión de la Estadística General del Reino (1856-1861), sustituida por la Junta General de Estadística (1861-1873) y posteriormente por el Instituto Geográfico y Estadístico (1873-1925), germen del actual Instituto Geográfico Nacional. El Organismo de Estadísticas comenzaría a elaborar a partir de 1870 la Topografía Catastral de España, con información parcelaria referida tanto a los núcleos de las ciudades como a sus entornos periurbanos (Muro, Nadal y Urteaga, 1996; Reguera Rodríguez, 1998: 240). A partir de 1861, Francisco Coello dirigió la realización de un catastro topográfico parcelario con la cartografía urbana (Quirós Linares, 2009). Los planos de Granada serían realizados entre 1867 y 1868 por Domingo Ramos Rodríguez y Alejandro María Arriola y López de Sagredo, cubriendo aproximadamente un 32\% de la superficie de la ciudad de aquel momento. Habría que esperar a la confección del mapa de la ciudad por el Instituto Geográfico y Estadístico en 1909 para que se retomaran y completaran los trabajos emprendidos por los técnicos de la Junta General de Estadística (Camarero Bullón, Ferrer Rodríguez y Nieto Calmaestra, 2012: 27-58).

En lo que concierne a los mapas catastrales del término municipal de Granada, éstos no comenzarían a plantearse hasta la Ley del Avance Catastral y Catastro Parcelario de 1906 y el reglamento de esta ley de 1913, constituyendo los primeros de ellos meros croquis catastrales. Los verdaderos planos parcelarios comenzarían a formalizarse en 1946, siendo aprobados en 1950 por la Delegación de Granada del Instituto Geográfico y Catastral (Ruiz Morales, 1996; Calatrava Escobar y Ruiz Morales, 2005: 79 y 82).

El estudio de la historia catastral, la cartografía y la estadística parcelaria de España está siendo abordado con gran profusión en los últimos años, en especial sobre los procesos que se dieron desde la segunda mitad del siglo XIX (Santos Pérez, 2012: 41-64), tras la elaboración de los 16 volúmenes del Diccionario geográfico-estadístico-histórico de España y sus posesiones de ultramar por Pascual Madoz (1845-50), la aprobación de la Ley de Medición del Territorio (1859) y la gestación de un proyecto de levantamiento catastral general de todo el país. También es abundante la producción científica relacionada con el Catastro de la Ensenada (Camarero Bullón, 2002: 61-88), que en el caso de la capital granadina fue realizado en 1752 (Domínguez Ortiz, 1990; Jiménez Serrano y Serrano Gutiérrez, 2004). 
Sin embargo, el periodo situado entre estos dos momentos históricos está menos estudiado, destacando el inventario realizado por Miguel Ángel Bringas Gutiérrez sobre el apeo y valuación general de 1818-1820 promovido por Martín de Garay. Nuestro trabajo se centraría en uno de los episodios más sobresalientes auspiciados por esta iniciativa gubernamental, el que fuera desarrollado en la capital del antiguo reino nazarí por quien a tal efecto fue nombrado director de la Estadística de Granada. Los avances cartográficos del siglo XIX y sus conocimientos matemáticos le permitieron a Francisco Dalmau representar con gran precisión el territorio granadino a partir de levantamientos planiméticos que hicieron uso del establecimiento de redes geodésicas de triangulación.

Los mapas que dirigió están dibujados con tintas de colores y aguadas, tratando de dar una impresión de relieve que diferenciase claramente las zonas con orografía agreste de las llanas, indicándose las que estaban dedicadas al cultivo. En ellos se abandonó el uso indiferenciado de símbolos orográficos, tan común en las cartografías territoriales de los siglos XVII y XVIII. El sistema escogido para representar la orografía consistió en aplicar intensos sombreados mediante aguadas de tinta negra, a menudo potenciadas con curvas paralelas discontinuas, que podrían ser un precedente del uso de isolíneas vigente en nuestros días.

Aunque para reflejar los distintos datos espaciales no se incluyó una leyenda con los símbolos, se dibujaron los elementos más característicos con el mismo tipo de signos. En la representación de los elementos morfológicos del paisaje se siguieron criterios gráficos similares, lo que denota que en todos ellos se definió una metodología y se establecieron previamente unos criterios de representación.

Destaca el uso cuidado de la tipografía y el empleo de escalas gráficas, expresadas en estos mapas en tres barras graduadas, una superior en varas castellanas, otra en el centro en "estadales de marjal de á once cuartas de vara»y una inferior en "estadales de fanega de á once tercias de vara», con una contraescala de 0 a 100, con diez divisiones. La conversión de la primera de ellas al Sistema Métrico Decimal permite obtener unas escalas ligeramente superiores a 1:5.000 en todos estos planos. En cuanto a la orientación, se empleó la rosa de los vientos con la flor de lis señalando al septentrión, si bien ésta difiere en cada mapa, dándose preponderancia a la mejor composición y encaje en el formato, frente a la convención actual de colocar el norte en la parte superior del eje vertical del mapa.

La metodología que hemos llevado a cabo para realizar este trabajo ha consistido en la georreferenciación de todos estos mapas sobre la cartografía actual, redibujando e interpretando los elementos representados. Al mismo tiempo se ha transcrito toda la información aún legible en las anotaciones de los márgenes laterales del ejemplar de 1819 conservado en el Archivo Municipal del Ayunta- 
miento de Granada (en adelante AMGR). Dicha copia habría estado basada en el mapa que se encuentra en el Archivo Cartográfico y de Estudios Geográficos del Centro Geográfico del Ejército (en adelante ACEGCGE), adscrito al Ministerio de Defensa de España, en el que, sin embargo, no se introdujeron las notas marginales (figura 1).

\section{FIGURA 1}

MAPAS TOPOGRÁFICOS DE LA CIUDAD DE GRANADA Y SU TÉRMINO CONSERVADOS EN EL AMGR (ARRIBA IZQUIERDA) Y EN EL ACEGCGE (ARRIBA DERECHA). ELEMENTOS MORFOLÓGICOS DE DICHOS MAPAS Y SECTORIZACIÓN DE LOS PAGOS AGRÍCOLAS

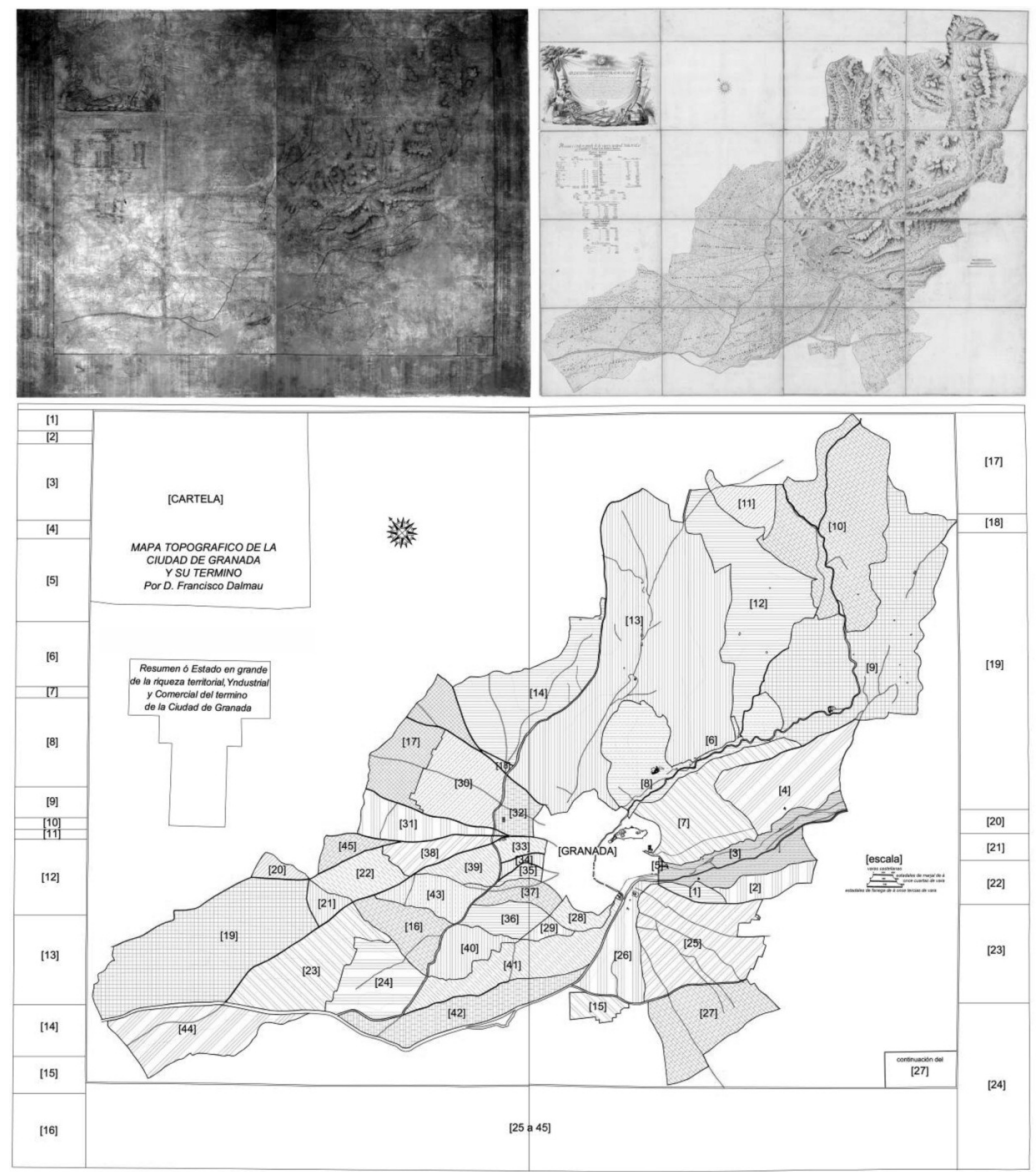

Fuente: Mapa Topográfico de la Ciudad de Granada y su Término (1819). 
Por ello se ha procedido a analizar otros dos documentos catastrales de esa década, tratando de localizar espacialmente en el mapa de 1819 los pagos agrícolas referidos en ellos. Los gráficos analíticos han sido obtenidos a partir de las bases de datos que se han elaborado con los datos disponibles.

\section{FRANCISCO DALMAU Y SU RELACIÓN CON LA CARTOGRAFÍA}

Francisco Dalmau nació en 1766 en el municipio barcelonés de Vilassar de Dalt-Cambrils, si bien quedaría vinculado a la ciudad de Granada desde los 24 años de edad hasta su muerte en 1824. A lo largo de su vida aunó amplios conocimientos de Matemáticas, Geografía, Topografía e Ingeniería, vinculándolos con la Literatura, Pedagogía y Filosofía. Estudió Ciencias en Barcelona y aprendió las aplicaciones prácticas de las matemáticas de Pere Gamell, artista y conservador del laboratorio de Física Experimental de la Real Academia de Ciencia Naturales y Artes de Barcelona.

En 1790 obtuvo la Cátedra de Matemáticas en la Real Maestranza de Caballería de Granada (Puig Pla, 2006, vol. I: 276-279), donde, entre otras asignaturas, impartiría Planimetría, Esfera y Cosmografía. Con este bagaje, en junio de 1795 solicitó al Cabildo la realización de un Mapa topográfico de la Ciudad de Granada en gran formato, terminándolo en diciembre de 1796 y realizándose un grabado del mismo en Madrid por Francisco Ribera, a escala 1/16 del original (Calatrava Escobar y Ruiz Morales, 2005: 71-82; Gámiz Gordo, 2008: 195-202; Juste Ocaña, 2008).

Francisco Dalmau se encontraba familiarizado con instrumentos especializados para el levantamiento cartográfico tales como la mesa geométrica, con su nivel de agua y la regla para las visuales y para levantar planos, la piris magnética con sus pínulas según Bion o el grafómetro para la medición angular horizontal que había inventado su maestro Pere Gamell (Puig Pla, 2000). Para la obtención de datos planimétricos de primera mano tuvo que poner a punto una metodología específica, basada en el trabajo de campo y en mediciones topográficas normalizadas, en un momento en el que existía en España un déficit de aparatos ópticos para la física experimental. De ahí que, entre sus prioridades tras obtener la Cátedra de Matemáticas, estuviese la adquisición de material para el laboratorio y la biblioteca de la Real Maestranza de Caballería de Granada.

Antes de 1804 realizaría el Mapa Topográfico Plano del Soto de Roma para Manuel Godoy, Primer Ministro de Carlos IV, así como el Plan del Río Genil desde la Ciudad hasta los Vados de la de Santa Fe, por Comisión del Ayuntamiento de Granada (Clemente Rubio, 2002: 198). 
En 1809 se cerró la Cátedra de Matemáticas, poco antes de que Granada fuese invadida por las tropas napoleónicas, periodo durante el cual aceptaría la dirección del Liceo Real José I (Barrios Rozúa, 2013: 116-118 y 277). Pese a estar entre los primeros inculpados tras la retirada francesa, fue pronto restablecido como profesor de matemáticas y el 4 de marzo de 1816 completaría el Mapa Geográfico de Parte del Reino de Granada y Jaén por encargo del Conde del Montijo, Capitán General del Reino y de la Costa de Granada, siendo presentado al Ministro de Estado de Fernando VII.

\section{El MAPA TOPOGRÁfico DE LA CIUDAD DE GRANADA Y SU TÉRMINO (1819): ANTECEDENTES Y CONTENIDOS}

Un repaso a las fechas en las que comenzaron a realizarse otras cartografías estadísticas y parcelarias españolas, permite comprender mejor el esfuerzo realizado por Francisco Dalmau al elaborar en 1819 el Mapa topográfico de la Ciudad de Granada y su término. En Barcelona, la Comisión provincial de Estadística dirigida por Enrique Antonio Berro favoreció que, entre 1849 y 1854, hasta 24 agrimensores catalanes trabajaran en el levantamiento de 83 mapas parcelarios correspondientes a 65 municipios (Nadal, Urteaga y Muro, 2006: 43-60). En el caso de la capital española no sería hasta 1866 cuando Carlos Colubi realizase el Plano Catastral del Término de Madrid, dividido en 36 hojas, con la representación de los Registros de la Propiedad de la periferia. Dichos trabajos fueron realizados en la misma década en que se gestó la Junta General de Estadística y la Escuela Especial del Catastro, con el objetivo de la formación de un cuerpo técnico especializado que efectuase el levantamiento del Catastro General en España (Urteaga, 2011: 29-53).

El fin último del mapa de 1819 era contribuir al recuento estadístico de la riqueza territorial de Granada, tal y como reza su cartela. Para ello era necesario elaborar un detallado catastro parcelario de rústica en el que se indicasen las fincas y propiedades particulares que conformaban cada uno de los pagos agrícolas que rodeaban al municipio granadino. Esta información quedó consignada en las anotaciones introducidas en los márgenes del ejemplar que fue copiado y ofrecido al Ayuntamiento de Granada (García-Pulido, 2013: 171-198), en cuyo Archivo Municipal se conserva, si bien ha sufrido un importante proceso de deterioro en su perímetro. Recientemente han aparecido en este archivo los cuadernos números uno, dos, ocho y nueve de los 17 que dirigió Francisco Dalmau sobre la Estadística General de la Capital de Granada. A grandes rasgos, los registros coinciden con los que hemos podido desentrañar de las abreviadas y malo- 
gradas notas marginales del mapa conservado en el AMGR, aunque hay algunos cambios en el orden de las parcelas y además la numeración es diferente, siendo correlativa en los cuadernos, frente a la del mapa, donde se empieza por el número uno en cada pago. Por ello, estamos realizando un laborioso trabajo de identificación y localización de cada parcela en el mapa, cuyo contenido supera ampliamente el trabajo que nos ocupa. Hasta que no salgan a la luz los 13 cuadernos restantes -en el caso de que se hayan conservado- dicho análisis no podrá verse culminado para ofrecer una visión global.

En la portada del primer cuaderno se especifican las causas de la elaboración de la «Estadística General de esta Capital de Granada, hecha, de mandato de los Señores de la Junta de la Contribución general del Reino, y su mensura practicada por el Profesor de Matemáticas don Francisco Dalmau. Vecino de ella, nombrado para dicho efecto, y la tasación de las Tierras, numero de su Arbolado y demás frutos que produce por los Peritos don Florencio Texeiro, don Josef Ximenez, y don Francisco Roman».

En la contraportada se aportan algunos datos complementarios: «Ciudad de Granada. Contribución general del Reino. Año de 1819. Diez y siete cuadernos que expresan la riqueza territorial, industrial, y comercial que ha tenido esta Ciudad en el año próximo pasado de 1818, medidas las fincas, y clasificadas con distinción por don Francisco Dalmau, individuo agregado a la Junta principal para S. M. y nombrado al efecto por la Junta de Contribución, regulados los valores de los Capitales, productos, y clase de ellos y demás, por don Florencio Tejeiro, don Josef Ximenez y don Francisco Roman, Peritos nombrados por la Junta de Contribución en conformidad del Articulo 13 de la Real Instrucción de $1^{\circ}$ de Junio de 1817 ».

Los datos parcelarios de estos cuadernos también quedaron organizados por pagos agrícolas, indicando en columnas el número de cada posesión, la clase (haza, huerta, alameda, avellaneda, dehesa, casa, carmen, molino, cueva...) y su calidad (regadío o secano), el propietario y arrendatario, el número de árboles, la superficie en fanegas y estadales (fundamentalmente para los cultivos de secano) o en marjales y estadales (en general para las parcelas de regadío), la producción en especie (frutas, aceite, cebada, trigo, legumbres, avellanas, vino...), el valor de la finca, la renta que se pagaba y su producción en reales de vellón.

En la banda de la margen del lado izquierdo del mapa conservado en el AMGR se indicaron los datos de 16 pagos, con un total de 556 parcelas y 212 cuevas en el Sacromonte y en el Barranco del Abogado. La de la margen derecha contiene la mitad de los predios de mayor tamaño, en los que se representan hasta 651 parcelas. En la banda inferior, perdida casi en su integridad, se habrían relacionado los restantes 21 pagos agrícolas, con un total de 1304 pro- 
piedades. En total, el término granadino estaba compuesto según el mapa de 1819 por 45 predios que contenían un total de 2511 parcelas agrícolas, algunas de las cuales estaban a su vez subdivididas. Este dato -extraído directamente del conteo visible de los números de las parcelas dibujadas- contrasta con el de los cuadernos localizados, pues la última propiedad reflejada en el noveno libreto lleva el número 2476, por lo que los 17 cuadernos podrían contener en su totalidad entre 4000 y 5000 propiedades. Este hecho podría obedecer a que la información que se reflejó en el mapa se sintetizó, sobre todo en los predios más montuosos correspondientes al secano. Sin embargo, muchas de las propiedades inventariadas en los cuadernos se pueden localizar espacialmente en los límites parcelarios indicados en el mapa, donde a menudo en una única finca se aprecian tenues subdivisiones internas que reflejan varias subparcelas, a veces contabilizadas con un único número en las notas marginales.

Tras la Guerra de la Independencia se habían elaborado dos cuantiosos apeos de rústica de Granada y su término. El primero fue realizado en marzo de 1814 por José Palacios Herrera, regidor del Ayuntamiento de Granada ${ }^{2}$. En este documento se expresaron las posesiones, pagos, dueños labradores, número de marjales, clases de terrenos y profesiones de los vecinos que tenían propiedades en los pagos del ruedo de Granada. El segundo es de autor desconocido y se realizó en 1817 con objeto de recaudar deudas pendientes de las haciendas del término municipal granadino. Contiene una enumeración de las parcelas de una serie de predios, con indicación de los marjales, calidad de las huertas y tierras calmas, propietarios, labradores, su vecindad, rentas, utilidades y comercio ${ }^{3}$. Aunque la numeración de las posesiones y la estructura de los datos contenidos en estos apeos no siguen el mismo orden y criterio que los cuadernos elaborados por Francisco Dalmau a partir de las mediciones tomadas en 1818, el Repartimiento de 1817 nos ha servido para estudiar con más detalle la estructura de la propiedad en los pagos agrícolas del término municipal de Granada en ese momento. Para verificar el grado de fiabilidad de este documento, hemos comparado dos de los predios cuya información se ha conservado íntegra en los cuadernos dirigidos por el autor del mapa. Así por ejemplo, el afamado pago de Aynadamar y Alquería del Fague contaba con 135 parcelas en 1818, si bien en el documento de 1817 correspondería a los pagos de Albayzín y Aynadamar y Alquería del

\footnotetext{
2 Archivo Municipal del Ayuntamiento de Granada (en adelante AMGR), legajo 1172, piezas $48-52$.

${ }^{3}$ AMGR, legajo 16741, Repartimiento de 318.270 reales que deven exigir á las haciendas del termino de ésta Ciudad, puertas afuera de su cargo, con espresion y distinción de la parte de propiedad, de industrial y comercial, que se regula á cada uno de los que deven ser contribuyentes.
} 
Fargue, que sumaban un total de 126. Las parcelas medidas en marjales, asimilables en gran parte al regadío, vendrían a ocupar una superficie relativamente próxima. Sin embargo, hay mucha más diferencia en el área expresada en fanegas, que correspondería en buena parte al secano. Algo similar ocurriría en el inmediato pago de Cújar, donde el número de marjales de regadío resulta más equiparable en estos dos documentos prácticamente coetáneos que el de las fanegas de secano. Este hecho parece translucir que las tierras de secano de los pagos de monte o de pie de monte no se midieron en su globalidad en la más antigua de estas estadísticas. También hay que indicar que, en los más ricos y completos registros del apeo catastral de 1818 se indica una realidad mucho más variada y compleja, con tierras medidas en fanegas en las que también se daba parcialmente el regadío, lo que también ocurre a la viceversa en algunas parcelas cuya superficie se expresa en marjales (figura 2).

Dado que una buena parte de las anotaciones marginales que se introdujeron en el mapa de 1819 se han perdido y que, las que ahora estamos analizando derivadas de los cuatro cuadernos aparecidos en el AMGR corresponden a algo menos de un cuarto de la información total de los pagos agrícolas granadinos, hemos procedido a estudiar el Repartimiento realizado en 1817, que contiene correcciones, modificaciones y ampliaciones que se prolongan hasta 1821. En dicho inventario muchos de los pagos agrícolas se agruparon por cercanía, lo que a priori parecería explicar por qué tan solo se relacionaron 22 predios $^{4}$ en lugar de los 45 señalados en el mapa de 1819. Sin embargo, tras transcribir los datos y calcular las superficies en hectáreas, encontramos que en el Repartimiento se incluyeron 3.995,91 ha de regadío en 1.593 parcelas (con un promedio de 2,51 ha/parcela de primera, segunda y tercera calidad), frente a las 2.511 parcelas agrícolas y $4.901,81$ ha que resultan de los datos del cuadro resumen del mapa de Francisco Dalmau, correspondientes a los cultivos herbáceos, olivar y viña irrigados. Otro tanto le ocurre a las superficies destinadas al secano, en el que se reflejaron $1.779,26$ ha en 90 grandes parcelas, con un promedio de $19,77 \mathrm{ha} /$ parcela, frente a las $2.851,37$ ha que resultan del mapa de 1819 , de las que $2.767,52$ ha eran tierras cultivadas y 85,85 ha se incluían en monte alto y bajo. Esto hace que la superficie cultivada de regadío y secano reflejada en el cuadro resumen de dicho mapa ascienda a 7.753,18 ha frente a las 5.775,17 ha

${ }^{4}$ Faraguit Alto y Bajo, Arabial Alto y Bajo, Camaura Alta y Baja, Canacha, Gira Román y Eras de San Jerónimo, Montones, Arabenal, Zaidín, Arabuleyla, Ribera y Pedregales del Genil, Alcalay y Tafia, Tercio y Cuartillo, Ofra, Macharatalán, Cújar, Almanjáyar Alto y Bajo, Marachuchi, Albayzín y Aynadamar, Alquería del Fargue, Cármenes del Darro, Almecín Alto y Bajo y Alhambra. 


\section{FIGURA 2}

DETALLE DEL PAGO DE AYNADAMAR Y ALQUERÍA DEL FARGUE EN EL MAPA TOPOGRÁFICO DE LA CIUDAD DE GRANADA Y SU TÉRMINO DE 1819, CON LA DISTRIBUCIÓN DE LAS PARCELAS DE REGADÍO Y SECANO SEGÚN LAS NOTAS MARGINALES DEL MAPA Y EL PRIMER CUADERNO DE LA ESTADÍSTICA GENERAL DE LA CAPITAL DE GRANADA, DIRIGIDA POR FRANCISCO DALMAU

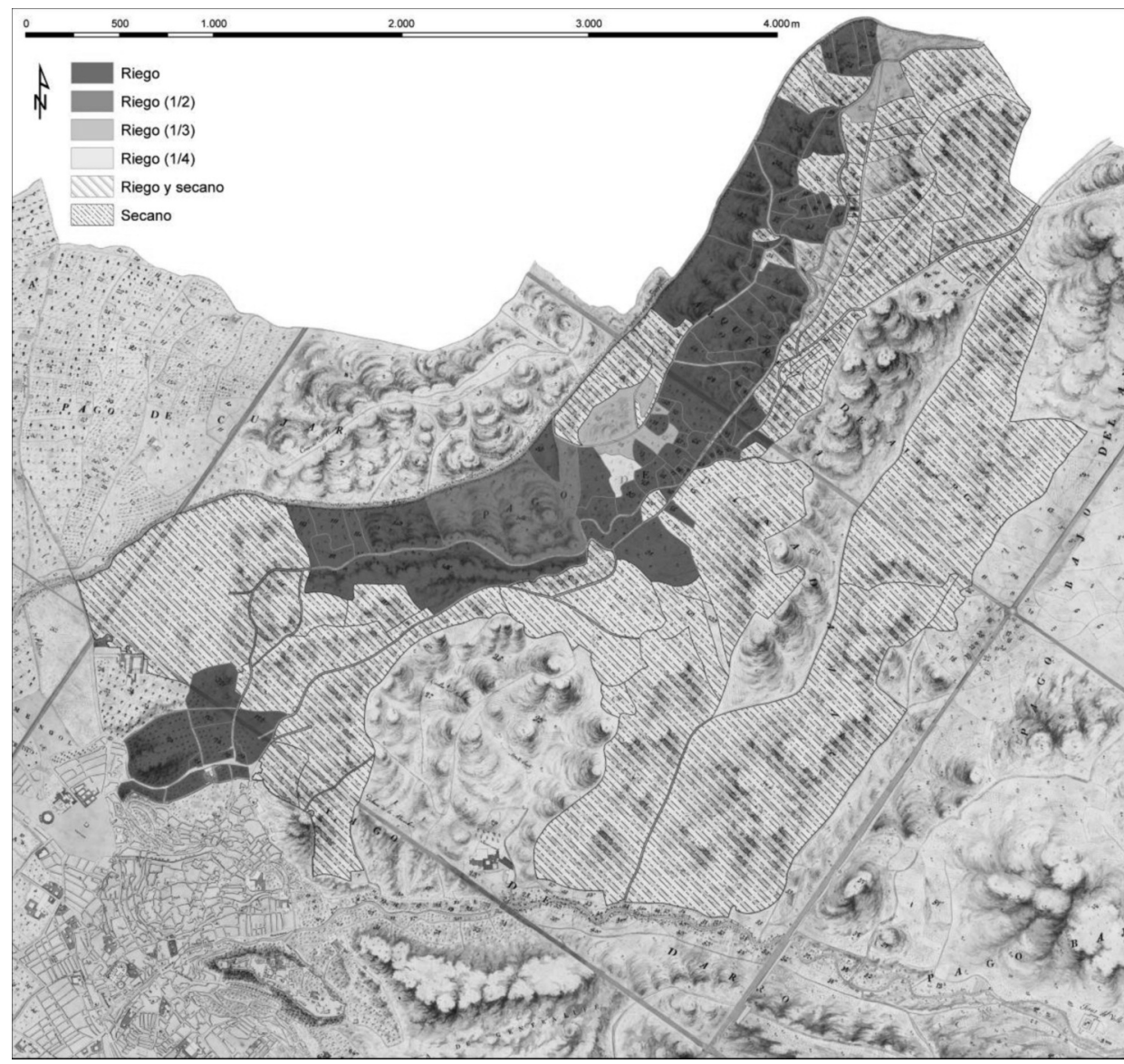

Fuente: Mapa Topográfico de la Ciudad de Granada y su Término (1819) y Primer Cuaderno de la Estadística General de la Capital de Granada (1818). 
FIGURA 3

DATOS RELATIVOS A LAS PARCELAS DE REGADÍO CONTENIDOS EN EL REPARTIMIENTO DE LAS HACIENDAS DEL TÉRMINO DE GRANADA EN RELACIÓN AL MAPA TOPOGRÁFICO DE LA CIUDAD DE GRANADA Y SU TÉRMINO DE 1819

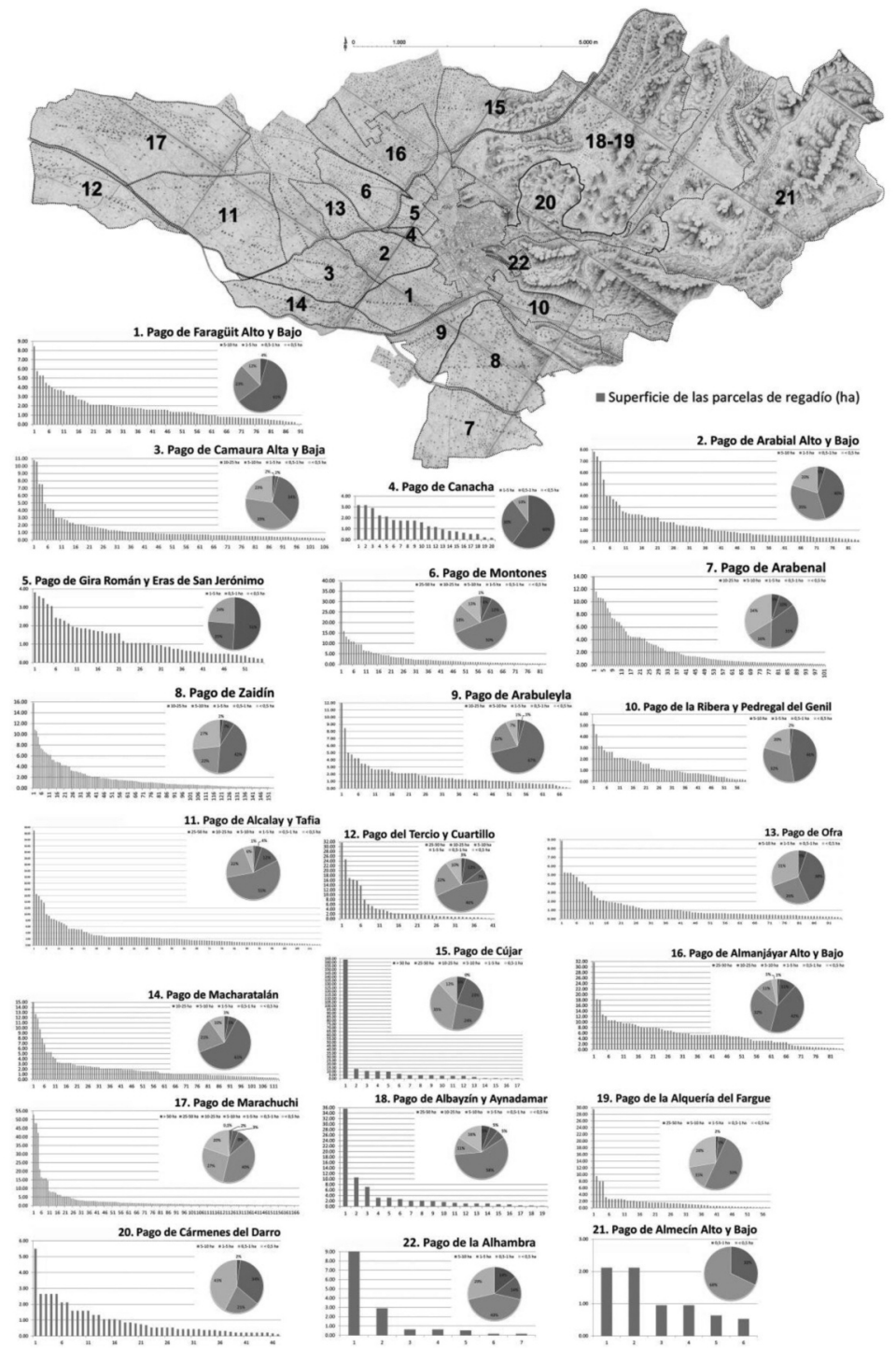

Fuente: Mapa Topográfico de la Ciudad de Granada y su Término (1819) y Legajo 16741 del AMGR.

Estudios Geográficos, Vol. LXXVII, 280, pp. 155-190, enero-junio 2016

ISSN: 0014-1496, eISSN: 1988-8546, doi: 10.3989/estgeogr.201606 
del documento de 1817. Esta diferencia en torno a las 1.000 ha en los cultivos de regadío y otro tanto en los de secano, confirma que no todos los predios agrícolas reflejados en el mapa de 1819 fueron contemplados en el apeo de 1817, además no se habrían reflejado la totalidad de las parcelas, como ha quedado puesto de manifiesto para el caso de las hazas de secano que se relacionan en varios pagos. Por tanto los valores obtenidos del Repartimiento no deben considerarse como globales, pues puede que las haciendas que no tuviesen deudas con el fisco no hubiesen sido peritadas.

Así, en el regadío no se hace mención a los pagos de Santillana, Naujar y Frigiliana, Mocatea, Madrasa, Media Hoz y Ramal de Pinos, Las Bellotas y Arcaduz, Fatinafa y Villaviciosa, todos ellos situados en el mapa de Francisco Dalmau en la franja periférica del término de Granada. Tampoco parecen estar incluidos los predios denominados Quinta Alegre, Revite, Dehesa de la Alhambra y Dehesa del Generalife, donde predominaba el secano.

Pese a todas estas limitaciones, el documento de 1817 sigue ofreciendo por ahora la visión más amplia y sistemática de la estadística parcelaria reflejada en el mapa de 1819 (figura 3), hasta tanto no contemos con todos los cuadernos elaborados por Francisco Dalmau, que contendrían el pormenorizado estudio realizado en 1818 con su equipo de peritos.

\section{ANÁlisis geOgráfico-PAisAJístico del maPA de Francisco Dalmau de 1819}

\section{Usos del suelo}

Con lo que sí contamos en el mapa de 1819 es con las seis tablas del «resumen de la riqueza territorial, industrial y comercial del término de Granada», en las que se computaron en marjales y fanegas los valores de la estadística parcelaria correspondiente al año anterior, dejando constancia de los resultados del estudio realizado sobre el municipio granadino. Las tres primeras tablas corresponden a la riqueza territorial, dedicadas las dos superiores a la agricultura (una para las clases de terreno de secano y regadío y otra para los productos agrícolas obtenidos) y la tercera a la ganadería. Un cuarto cuadro está destinado al recuento de edificios extramuros de la ciudad, contabilizándose 138 caseríos y cortijos, 31 molinos harineros y 15 papeleros. La riqueza industrial quedó reflejada en dos tablas, una con indicación de las fábricas extramuros de la ciudad y otra dedicada a los oficios y artes que se desempeñaban en las fincas periurbanas.

Del análisis de estos datos se obtiene que las parcelas de regadío sumaban 4.249,37 ha, aproximadamente un 48,28\% de la superficie actual del término 
municipal de Granada ${ }^{5}$. Predominaban las tierras calmas de tres calidades, destinadas fundamentalmente al cereal, aunque también había otros cultivos herbáceos, ocupando un $82 \%$ de la superficie total. Ésta es solo un $6,17 \%$ superior a las 4.003,04 ha que fueron calculadas en 1752 con ocasión del Catastro de la Ensenada (Domínguez Ortiz, 1990: 45-45), pues el sistema hidráulico granadino de origen medieval que permitía el regadío seguía siendo el mismo y la ciudad apenas se había expandido sobre zonas de cultivo en esas casi 7 décadas. El olivar y el viñedo se plantaban cada uno en un $8 \%$ de la superficie cultivada. Apenas un 2\% estaba representado por el arbolado productivo (álamos, mimbres y chopos), y la exigua parte restante estaba destinada a avellaneras (figura 4). Las moredas y morales que otrora fundamentaron la industria de la seda granadina no aparecen ya reflejados en los cuados resúmenes de este mapa, mientras sí lo hacen aún en 1752, entremezclados con olivos y frutales.

FIGURA 4

DISTRIBUCIÓN DE LA TIERRA DE REGADÍO A PARTIR DE LOS DATOS DEL MAPA TOPOGRÁFICO DE LA CIUDAD DE GRANADA Y SU TÉRMINO DE 1819

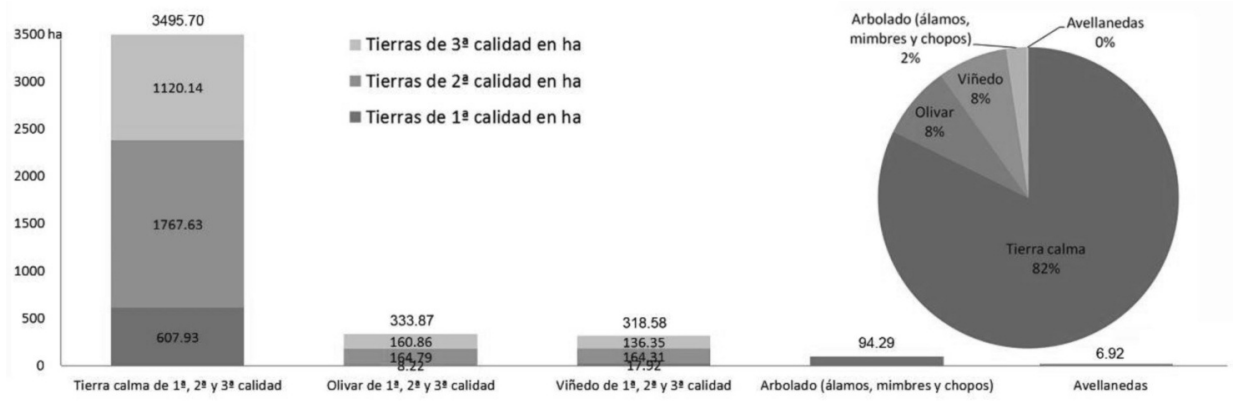

Fuente: Mapa Topográfico de la Ciudad de Granada y su Término (1819).

Las tierras de secano ocupaban un total de 2.851,37 ha, lo que correspondería a un $32,39 \%$ del término municipal presente. En este caso, la superficie es menor de las 3.432,76 ha relacionadas en el Catastro de la Ensenada. Se distribuían principalmente en los pagos situados al este de la ciudad, por encima de los valles de los ríos Genil, Darro y Beiro, así como en aquellas zonas a las que

${ }^{5}$ En nuestros días asciende a 8802 ha, aunque sus límites han sufrido algunas modificaciones respecto a los que aparecen reflejados en el mapa de 1819, como por ejemplo la incorporación del pago de Tarramonta (91,50 ha), antes perteneciente a Churriana de la Vega, o la pérdida del pago de Villaviciosa (unas 12 ha), hoy englobado en Armilla. 
no podía llegar la extensa red de acequias de Granada. En ellos predominaba con un $95 \%$ la tierra calma de tercera calidad. Sorprende el hecho de que el monte alto y bajo se reduzca tan solo al 3\% (83,85 ha frente a las 297,66 ha que sumaban en 1752), lo que debe de indicar que todas las zonas de dehesa que existieron a levante de Granada se encontraban muy esquilmadas a principios del siglo XIX, pudiendo haberse visto afectadas durante los desórdenes y sobreexplotación de los recursos naturales que acompañaron a la invasión napoleónica. Actualmente el olivar está concentrado en estos pagos de secano, si bien en 1818 solo sumaba 50,73 ha, frente a las 333,87 ha en los pagos de regadío (figura 5).

\section{FIGURA 5}

DISTRIBUCIÓN DE LA TIERRA DE SECANO A PARTIR DE LOS DATOS DEL MAPA TOPOGRÁFICO DE LA CIUDAD DE GRANADA Y SU TÉRMINO DE 1819

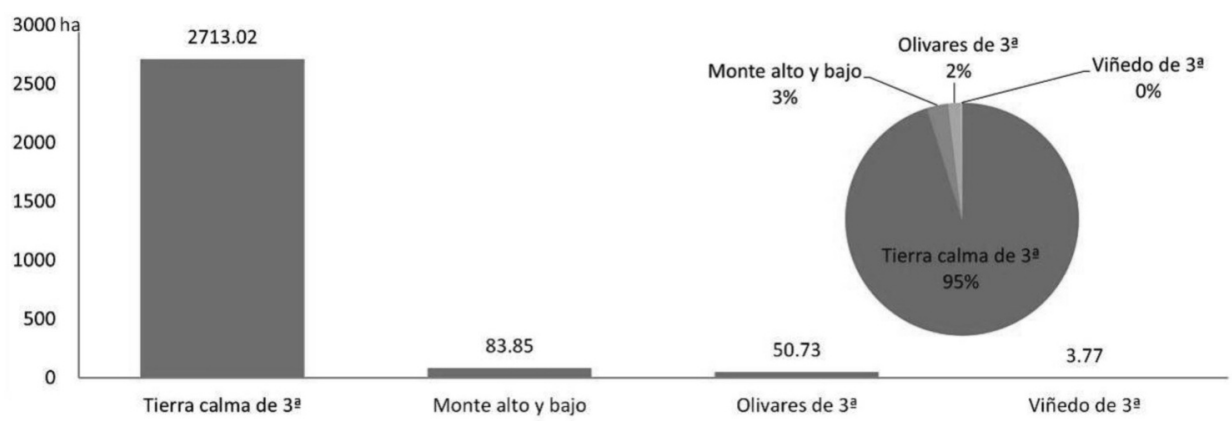

Fuente: Mapa Topográfico de la Ciudad de Granada y su Término (1819).

Las rotaciones normales de los campos de cultivo duraban cuatro años en los que, tras el estercolado, se plantaban habas en el primer año, trigo en el segundo, lino en el tercero y de nuevo trigo antes de volver a abonar (Ocaña Ocaña, 1974: 335-336). Por ello no es de extrañar que, en el caso de los pagos agrícolas de Granada, el 67\% de la masa producida en 1818 fuese de trigo, el $21 \%$ de habas, el $9 \%$ de cebada y solo menos del 1\% de maíz. Tras la expulsión de las tropas invasoras francesas hubo que volver a poner en marcha los mecanismos productivos, imponiéndose en el territorio granadino el cultivo del cereal para atender las necesidades más inmediatas de la población (Viñes Millet, 2004: 94). La considerable reducción de la dehesa granadina que se aprecia entre 1752 y 1818 está en consonancia con la exigua recolección de bellota de encina, que solo representaba el $1 \%$. Apenas otro tanto restante estaba destinado a la plantación de diversos cultivos herbáceos, que por este orden eran las judías, 
guijas, yeros, garbanzos, mijo, alazor y lentejas, así como un muy pequeño porcentaje de otro cereal, el centeno. En lo relativo a los productos medidos en volumen destaca el vino con un 56\%, seguido del cáñamo con un $20 \%$ y el lino con un $16 \%$. El aceite, por el contrario, solo representaba el 6\%, pues, pese a que la superficie de regadío del olivar era casi la misma en términos absolutos que la del viñedo, las viñas de primera calidad triplicaban a los olivos de la misma categoría. Por último se encontraban las avellanas que se producían en abundancia en el valle del río Darro y que representaban el 2\% (figura 6).

\section{FIGURA 6}

PRODUCCIÓN DEL TÉRMINO MUNICIPAL GRANADINO A PARTIR DE LOS DATOS DEL MAPA TOPOGRÁFICO DE LA CIUDAD DE GRANADA Y SU TÉRMINO DE 1819

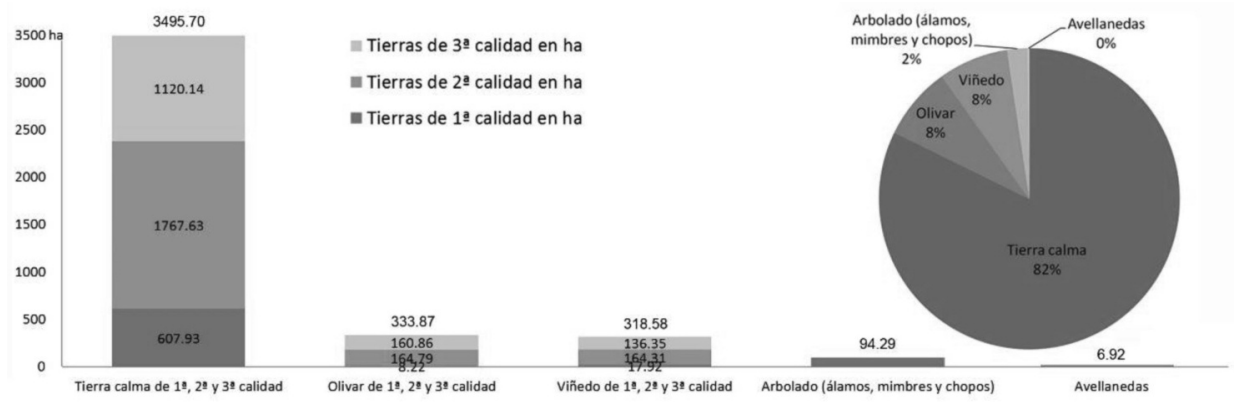

Fuente: Mapa Topográfico de la Ciudad de Granada y su Término (1819).

Hasta el último cuarto del siglo XIx en que se introdujo el monocultivo de la remolacha para la pujante industria azucarera, la Vega de Granada mantuvo un cultivo de rotación con la preeminencia de los cereales, sobresaliendo el trigo en el regadío, seguido muy de lejos por la cebada para alimentar al ganado. En dicha rotación entraba la plantación del lino y del cáñamo, habiendo constancia de la producción y exportación del primero de ellos desde la Edad Media, tal y como refirió al-Himyari (siglos XIII-XIV): «En cuanto al lino que se cultiva allí es de calidad superior al del valle del Nilo; la cosecha es tan abundante que se lleva a los países musulmanes más lejanos» (Lévi-Provençal, 1938: 30-31). El cáñamo habría sido introducido tras la conquista cristiana de Granada, siendo objeto de gravamen desde el primer momento. Ambos cultivos necesitaban gran cantidad de agua, por lo que se extendieron sobre tierras de buena calidad y bien abastecidas por acequias. El lino predominó sobre el cáñamo hasta mediados del siglo XviII, como manifiestan las estadísticas del Catastro de la Ense- 
nada en diversos pueblos de la Vega, pero a partir de este momento le iría ganando la partida la última planta, dado el privilegio concedido a la comarca para aprovisionar a la marina nacional en el arsenal de Málaga (Ocaña Ocaña, 1974: 340). Hasta mediados del siglo XVIII la fibra del cáñamo se importaba del norte, lo que encarecía el producto, por lo que el Gobierno vino a favorecer la expansión de su cultivo en la Vega granadina, y así, en los primeros años del siglo xIX se llegaron a producir alrededor de $2.000 \mathrm{Tm}$ (Morell Terry, 1888: 66). Estos cultivos estaban en alza en el momento en el que Francisco Dalmau dirigió los Mapas Topográficos del Partido de Granada, pues no solo se habían constituido en el siglo xviII en un valor refugio tras la crisis de la industria de la seda, sino que convertirían a la Vega de Granada en una de las comarcas más productivas de España y de Europa (Lorenzo Rojas, 2009: 417). En la cartela del mapa de 1819 se menciona la existencia de dos Reales Fábricas de Lona instaladas en Granada y, entre los elementos que la orlan, aparecen representados un barco y otros pertrechos navales, así como cordeles y lonas que habrían sido realizados con estas fibras naturales. Empezaron a entrar en declive con la decadencia general de las hilaturas bastas que se produjo tras la aparición de los tejidos industriales, así como por la desaparición del privilegio que tenía esta Vega para el cultivo del cáñamo, hundiéndose definitivamente con el decreto-ley de 23 de julio de 1883, en el que, junto al lino, quedaban gravados con un impuesto diez veces superior al de otros como el yute o la pita (Ocaña Ocaña, 1974: 341).

\section{La estructura de la propiedad de la tierra granadina en las décadas previas} a la Desamortización

Del Repartimiento de 1817 se pueden extraer múltiples datos geográficos en relación a la estructura y titularidad de la propiedad granadina en los años posteriores a la Guerra de la Independencia y poco tiempo antes de que se produjese el proceso de Desamortización, que vendría a modificar sustancialmente la posesión de la tierra.

Los 22 pagos agrícolas reflejados en dicho documento tuvieron todos tierras de regadío, si bien en los que se encontraban en la zona montuosa a levante de la ciudad se registraron grandes parcelas de secano. En cuanto a los tamaños de las propiedades irrigadas, un alto número contaban entre 1 y 5 ha (726 de un total de 1.593), sumando $1.531,68$ ha, y casi otro tanto (676) estaban por debajo de una hectárea. En el secano, también el mayor número de parcelas se encontraban en estas franjas ( 26 y 21 , respectivamente, de las 90 totales), aunque existían 7 grandes propiedades de más de 50 ha que sumaban en total 1.109,32 ha (figura 7). 


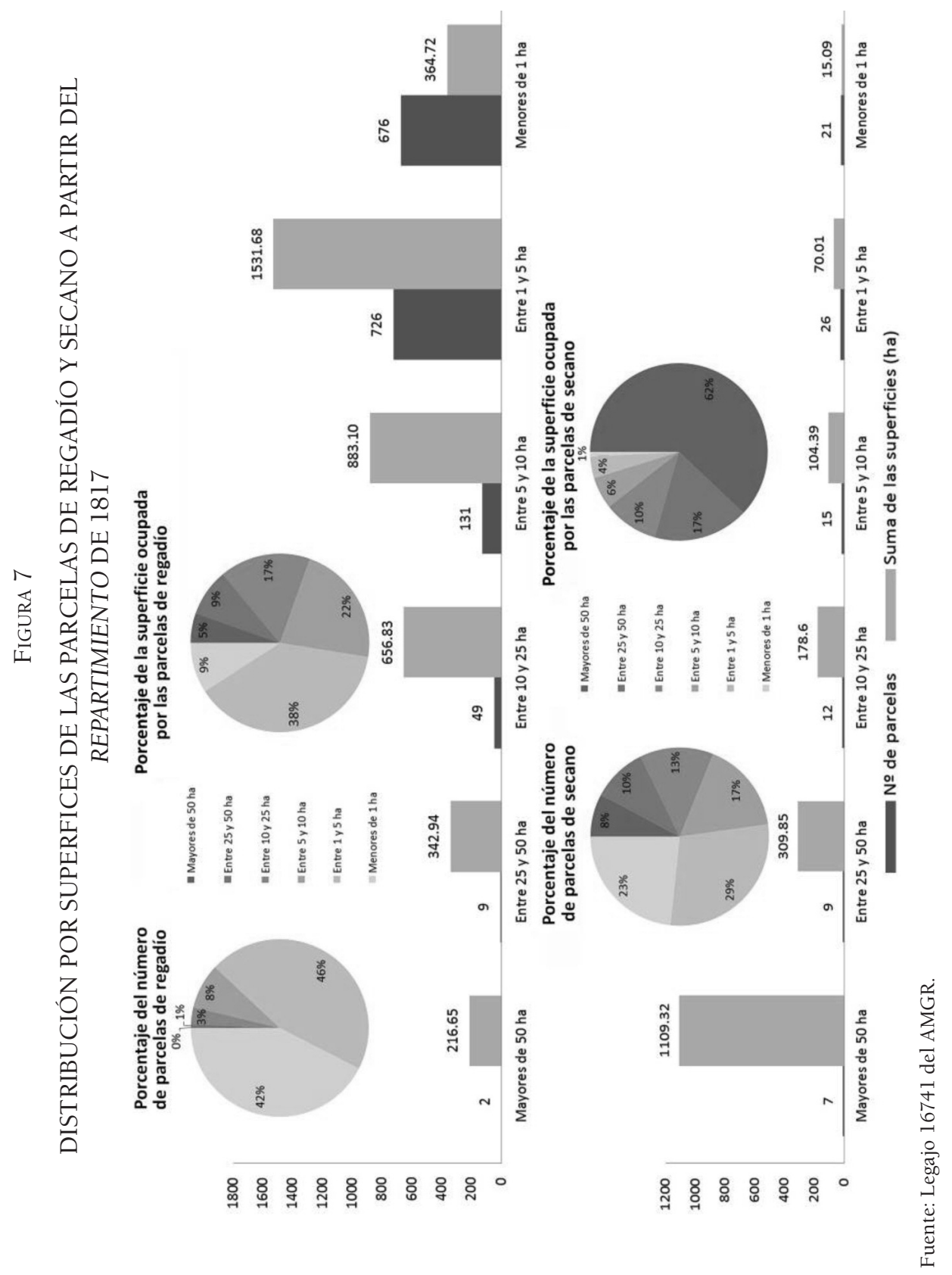


Como cabría esperar, en estos momentos previos a la Desamortización, las haciendas de mayor tamaño estaban en manos de miembros del estamento eclesiástico o de la nobleza. El patrimonio de las instituciones religiosas fue muy bien dotado tras la conquista cristiana de la ciudad y continuó acrecentándose hasta la primera mitad del siglo XIX. En total tenían propiedades en el término municipal de Granada 25 conventos, 7 monasterios, 4 iglesias, 4 hospitales, 2 congregaciones, 2 colegiatas, una capellanía, una sacristía y un cabildo (figura 8). Podríamos destacar la gran parcela de 163,81 ha de regadío junto a otra no irrigada de 41,92 ha que el

\section{FIGURA 8}

DISTRIBUCIÓN DE LAS TIERRAS PERTENECIENTES AL ESTAMENTO ECLESIÁSTICO POR SUPERFICES Y PARCELAS DE REGADÍO A PARTIR DEL REPARTIMIENTO DE 1817

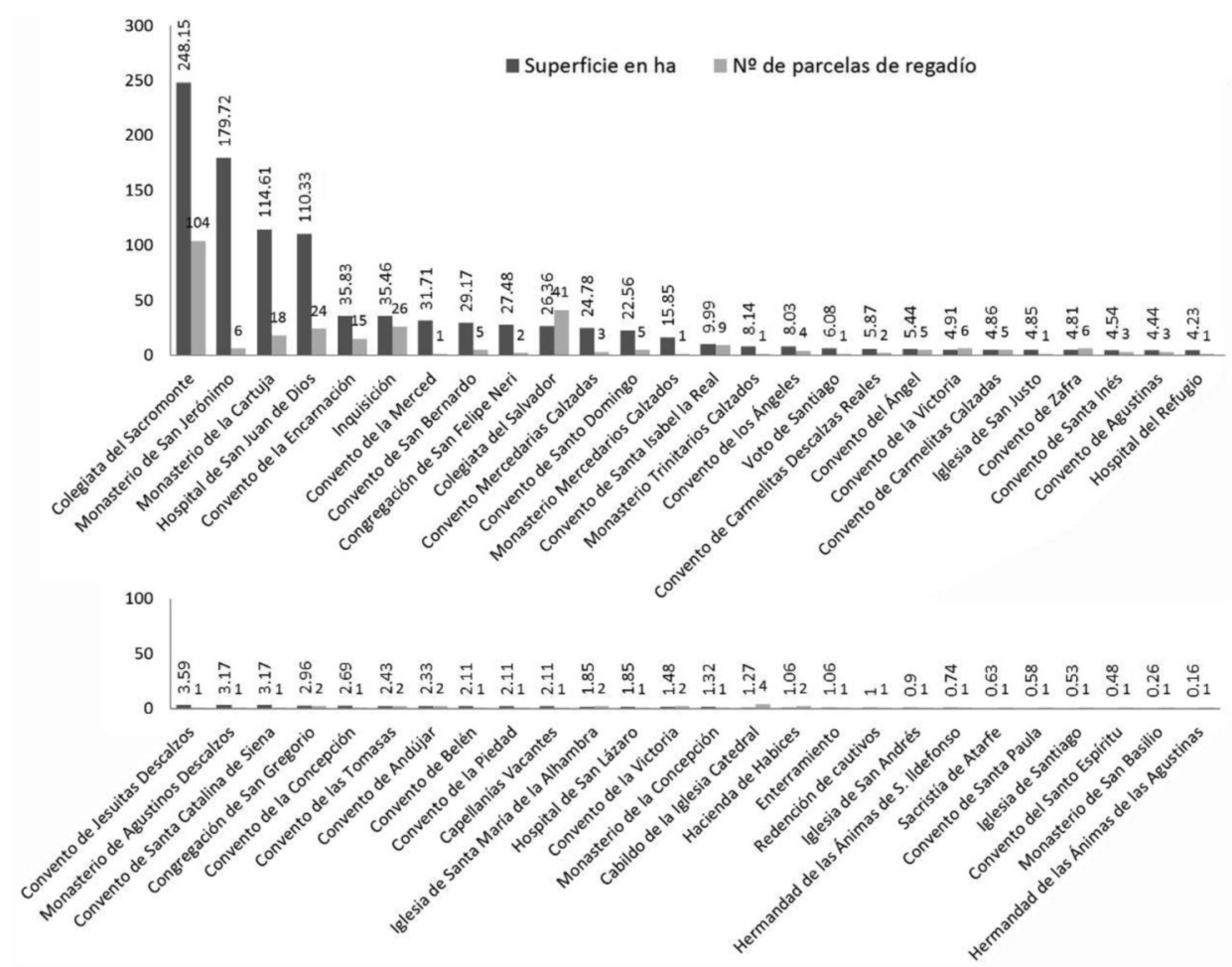

Fuente: Legajo 16741 del AMGR. 
FIGURA 9

DISTRIBUCIÓN DE LAS TIERRAS PERTENECIENTES A LA NOBLEZA POR SUPERFICES Y PARCELAS DE REGADÍO A PARTIR DEL REPARTIMIENTO DE 1817

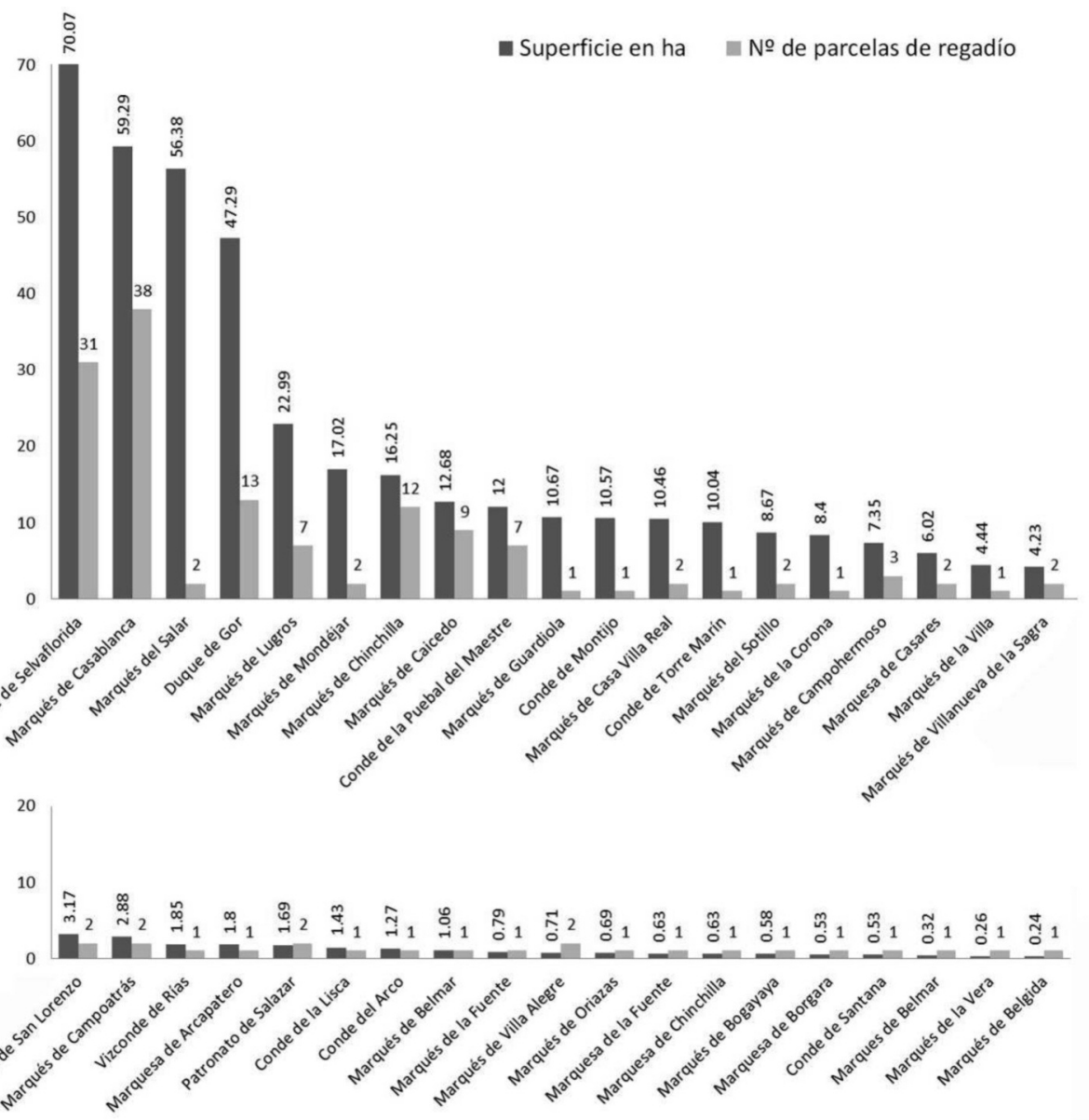

Fuente: Legajo 16741 del AMGR. 
Monasterio de San Jerónimo tenía en el pago de Cújar, las 125,77 ha de secano del Convento de la Encarnación en la Alquería del Fargue, las 52,84 ha de la Colegiata del Sacromonte en el pago de Marachuchi, las 35,67 ha de regadío más 57,02 ha de secano del Monasterio de la Cartuja en el pago de Aynadamar o las 31,71 ha del Convento de la Merced en los pagos de Almanjáyar alto y bajo. En el cómputo global de tierras detentadas sobresale la Colegiata del Sacromonte, con 248,15 ha de regadío en 104 propiedades y 16,77 ha de secano, o el caso de la Colegiata del Salvador, con 41 pequeñas hazas que solo sumaban 26,36 ha. La Inquisición aún poseía 26 parcelas en 1817 , con un total de 35,46 ha.

Entre los miembros de la nobleza destacan las 591,13 ha de secano pertenecientes al Duque de Gor en el Cortijo de Cortes (en el que también tenía 2,11 ha de regadío), las 31,71 ha del Marqués del Salar en el pago del Tercio y Cuartillo o las 15,80 y 14,06 ha de regadío respectivamente del Marqués de Lugros y del Marqués de Casa Villa Real en los pagos de Zaidín y Arabenal. En el cómputo global de tierras pertenecientes a los nobles sobresale de nuevo el Duque del Gor, quien poseía 47,29 ha de regadío en 13 parcelas y 285,08 ha de secano en los cortijos de Cortes y Cuesta, el Conde de Selvaflorida, con un total de 70,07 ha de regadío en 31 parcelas y el Marqués de Casablanca, con 38 parcelas que sumaban 59,29 ha. Destacan también dos grandes hazas de regadío del Marqués del Salar que sumaban 56,38 ha. En total, entre los nobles hacendados se contabilizan 27 marqueses, 7 condes, 2 duques y un vizconde (figura 9). Destaca también el caso de Juan Calderón quien, tras la expulsión de los Jesuitas de España unas décadas atrás, habría adquirido la gran hacienda construida por esta Orden en Jesús del Valle, con 591,13 ha de secano en los márgenes del río Darro.

En total la iglesia, la nobleza y el Patrimonio Real poseían $1.629,12$ ha en Granada en 529 parcelas de regadío y un total de 703,07 ha de secano en 14 hazas. En su conjunto asciende a 2.332,19 ha, lo que supone el 40,38\% de la superficie cultivada del término granadino reflejada en el Repartimiento de 1817.

\section{Los Mapas Topograficos del Partido de Granada de 1820}

Tras la elaboración del Mapa topográfico de la ciudad de Granada y su término, Francisco Dalmau dirigió otros 18 mapas de las villas y lugares que pertenecían al partido de la capital granadina (figura 10). 
FIGURA 10

GEORREFERENCIACIÓN DE LOS 19 MAPAS TOPOGRÁFICOS DE 1819 Y 1820, CORRESPONDIENTES AL TÉRMINO MUNICIPAL DE GRANADA Y A LOS LUGARES Y VILLAS DE SU PARTIDO

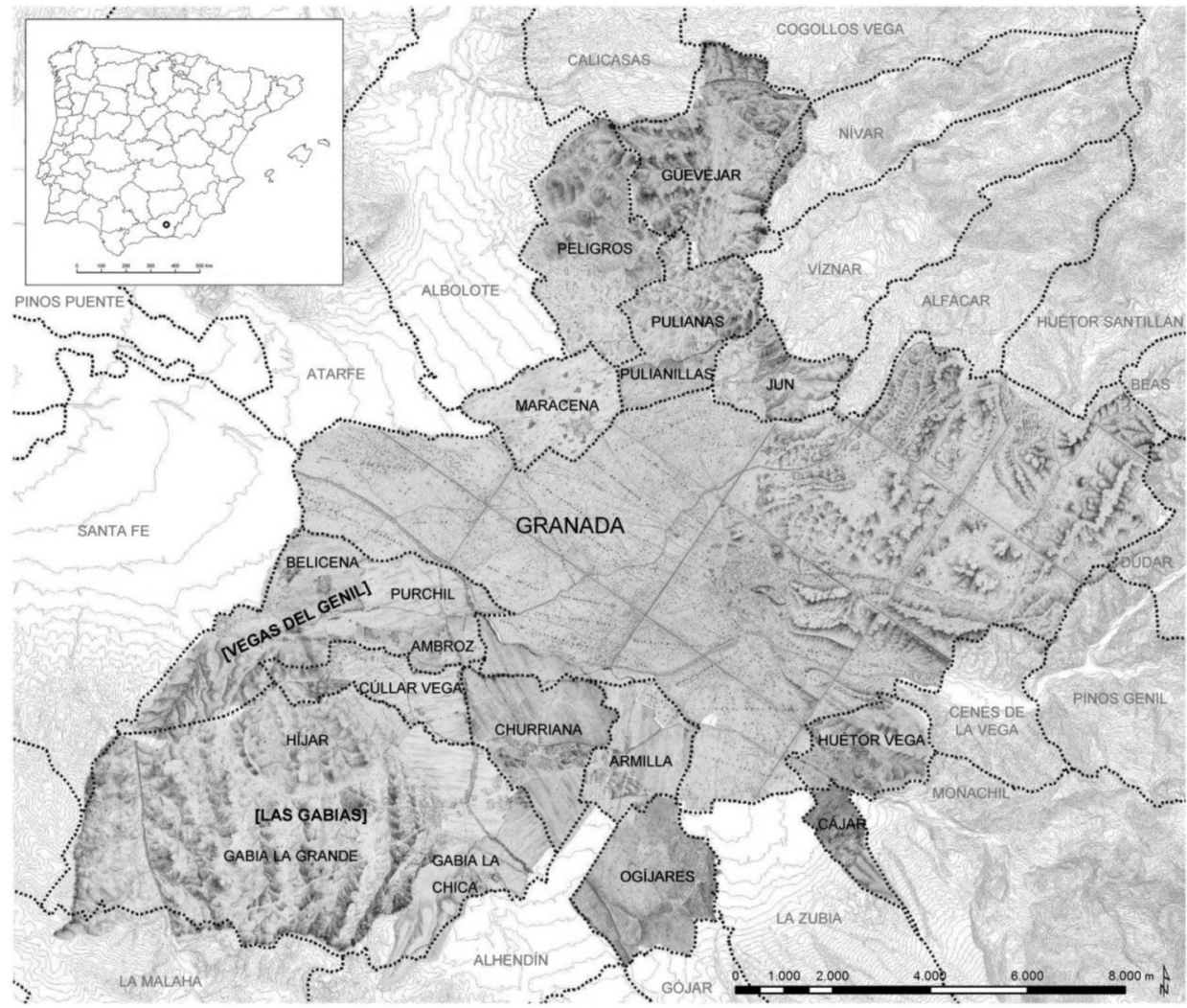

Fuente: Mapas topográficos número 218 a 236 (1819-1820) conservados en el ACEGCGE.

Además de su participación directa en algunos de los mapas, en la ingente tarea realizada en tan corto periodo de tiempo colaboraron una serie de personas, cuyos nombres aparecen rotulados en las cartografías: 


\begin{tabular}{|c|c|c|}
\hline Lugar / Villa & Levantado por: & Delineado y lavado por: \\
\hline GABIA LA GRANDE ${ }^{6}$ & Luis Delgado & $\begin{array}{l}\text { Manuel de Guruceta } \\
\text { Guruceta lo escribió } \\
\text { Pastor lo dibujó, y delineó }\end{array}$ \\
\hline GABIA LA CHICA & Ramón Robira Teruel & Santiago Marín \\
\hline HÍJAR & Dionisio López & $\begin{array}{l}\text { José Pastor } \\
\text { Emanuel Guruceta scripsit }\end{array}$ \\
\hline GÜEVÉJAR & José Rodríguez Llorente & Francisco Dalmau \\
\hline PELIGROS & Dionisio López & José Pastor \\
\hline HUÉTOR VEGA & Francisco Dalmau & Santiago Marín \\
\hline PURCHIL $^{7}$ & Dionisio López & Santiago Marín \\
\hline BELICENA & José Rodríguez Llorente & José Pastor \\
\hline AMBROZ & José Rodríguez Llorente & $\begin{array}{l}\text { Antonio Puchol } \\
\text { Manuel de Guruceta scripsit }\end{array}$ \\
\hline CÚLLAR VEGA & Ramón Robira Teruel & $\begin{array}{l}\text { Antonio Puchol } \\
\text { Guruceta fecit Inscripcionem }\end{array}$ \\
\hline MARACENA & José Rodríguez Llorente & Francisco [de] Granda \\
\hline $\begin{array}{l}\text { CHURRIANA } \\
\text { DE LA VEGA }\end{array}$ & Dionisio López & $\begin{array}{l}\text { Santiago Marín } \\
\text { Emanuel á Guruceta scripsit }\end{array}$ \\
\hline CÁJAR & Francisco Dalmau & $\begin{array}{l}\text { Santiago Marín } \\
\text { Emanuel á Guruceta scripsit }\end{array}$ \\
\hline OGÍJARES & Francisco Dalmau & $\begin{array}{l}\text { José Pastor } \\
\text { Manuel Guruceta scripsit }\end{array}$ \\
\hline JUN & Ramón Robira y Teruel [sic] & $\begin{array}{l}\text { José Pastor } \\
\text { Manuel Guruceta lo escribió }\end{array}$ \\
\hline PULIANAS $^{8}$ & Ramón Robira Teruel & Manuel [de] Guruceta \\
\hline PULIANILLAS & Francisco de Granda & Francisco de Granda \\
\hline$\overline{\text { ARMILLA }}$ & [NO SE INDICA] & Antonio Puchol \\
\hline
\end{tabular}

\footnotetext{
${ }^{6}$ Gabia la Grande, Gabia la Chica e Híjar están hoy englobados en el municipio de Las Gabias.

${ }^{7}$ Purchil, Belicena y Ambroz pertenecen en la actualidad al municipio de Vegas del Genil.

8 Pulianas y Pulianillas forman parte en nuestros días de un único municipio denominado Pulianas.
} 
En las Actas del Cabildo granadino correspondientes al 30 de diciembre de $1820^{9}$ se leyó un comunicado del Ministerio de la Gobernación, en el que, por acuerdo de las Cortes, el Gobierno designaba a Francisco Dalmau como «Director de la Estadística de Granada y otras provincias», dado los conocimientos demostrados y los méritos que había obtenido con los trabajos relativos a Granada y a los municipios de su partido.

Las cartelas de los mapas realizados en 1820 son diferentes en los elementos que las orlan, pero el contenido sigue siempre la siguiente estructura:

MAPA TOPOGRAFICO DE LA VILLA / DEL LUGAR DE ... Y SU TERMINO

En la Provincia de Granada, Partido de la Capital.

Esta situada su Yglesia á los $[\ldots]^{\circ}[\ldots]^{\prime}[\ldots]^{\prime}$ de latitud septentrional, y $[\ldots]^{\circ}[\ldots]^{\prime}[\ldots . .]^{\prime}$ de longitud, respecto al meridiano de la Ysla de Hierro. Su altura sobre el nivel de Mar, es de [...] $\mathrm{v}^{\mathrm{s}}$. [varas] [...] $\mathrm{p}^{\mathrm{s}}$. [pies] [...] puls. [pulgadas] [...] $\mathrm{l}^{\mathrm{s}}$. Contiene $[\ldots]$ casas, $[\ldots]$ almas ${ }^{10},[\ldots]$ fanegas de tierra de labor de secano, $[\ldots]$ marjales de riego, y [...] marjales de olivar, [...] marjales incultos, y [...] fanegas incultas.

\section{FORMADO DE ORDEN DE LA JUNTA PRINCIPAL DE CONTRIBUCION}

Por direccion de Dn. Francisco Dalmau. Año de 1820

No todos los campos de las cartelas llegaron a completarse, labor que fue realizada con posterioridad al texto inicial, dado la distinta grafía con que se consignaron los datos. En lo relativo al número de casas existentes a principios del siglo XIX (figura 11), precisamente los lugares que menor número tenían (Pulianillas, Ambroz, Gabia la Chica e Híjar), han acabado por englobarse en otros municipios de mayor envergadura. Destaca el caso de Gabia la Grande como núcleo con más viviendas, cuando hoy en día son las localidades más próximas a Granada las que cuentan con un mayor parque inmobiliario por actuar como ciudades dormitorio. Aunque en todos los casos se dejó en blanco el espacio destinado al censo de la población («almas»), el número de casas podría ser indicativo para estimar el número de habitantes existentes en estos municipios a principios del siglo XIX.

\footnotetext{
${ }^{9}$ Posterior al 9 de marzo, cuando Fernando VII juró la Constitución de 1812. Actas del Cabildo, 1820, AMGR, legajo L.00158, fols. $258 \mathrm{r}^{\circ}$ y $258 \mathrm{v}^{\circ}$.

${ }^{10}$ En ninguno de ellos se rellenó este campo. 
FIGURA 11

NÚMERO DE CASAS EXISTENTES EN GRANADA Y EN LOS LUGARES Y VILLAS DE SU PARTIDO EN 1820

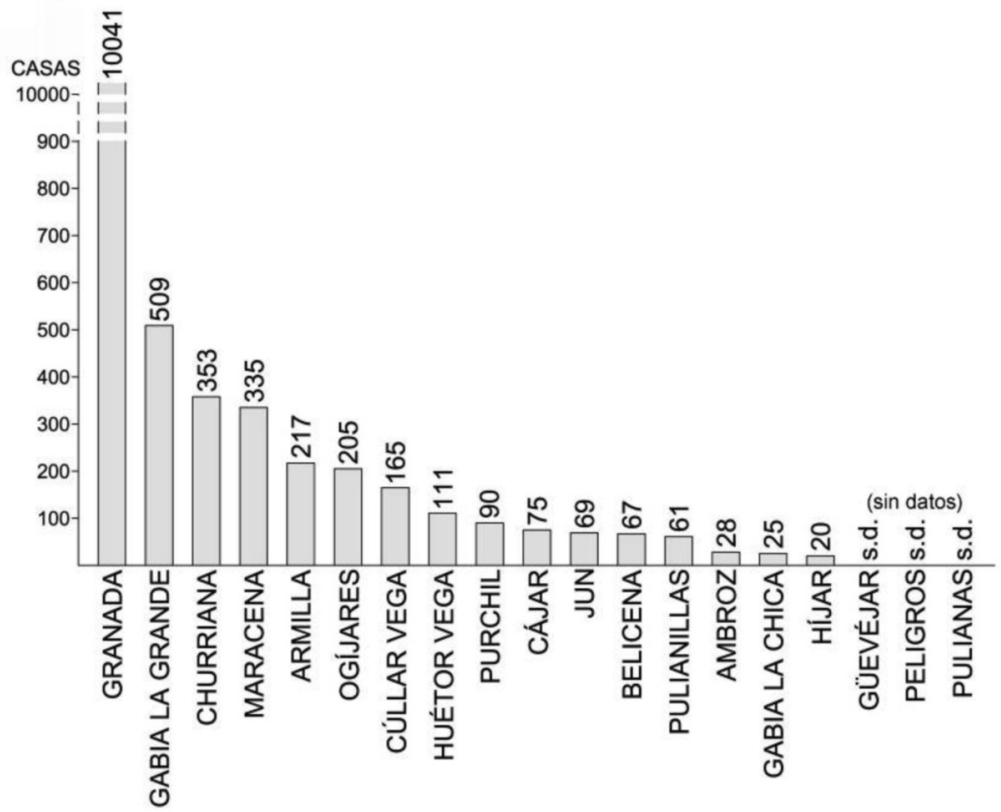

Fuente: Mapas topográficos número 218 a 236 (1819-1820) conservados en el ACEGCGE (los datos de la capital del partido se han obtenido del Mapa topográfico de la ciudad de Granada de 1796, pues en el de 1819 no fueron consignados).

En cuanto a las tierras de cultivo expresadas en estos mapas, destacan los casos de Granada, Ogíjares, Churriana de la Vega, Cúllar Vega y Cájar, con superficies destinadas al regadío en torno al 50\% (figura 12).

Las tierras de secano son sobre todo muy importantes en las tres poblaciones que hoy componen el municipio de Las Gabias (Gabia la Grande, Gabia la Chica e Híjar) y en Jun, donde la relación de éstas asciende a 2/3 de la superficie total de sus términos municipales actuales (figura 13). Este hecho se debe a tratarse de poblaciones situadas en zonas de ladera, más alejadas del núcleo más profusamente irrigado de la Vega de Granada. 


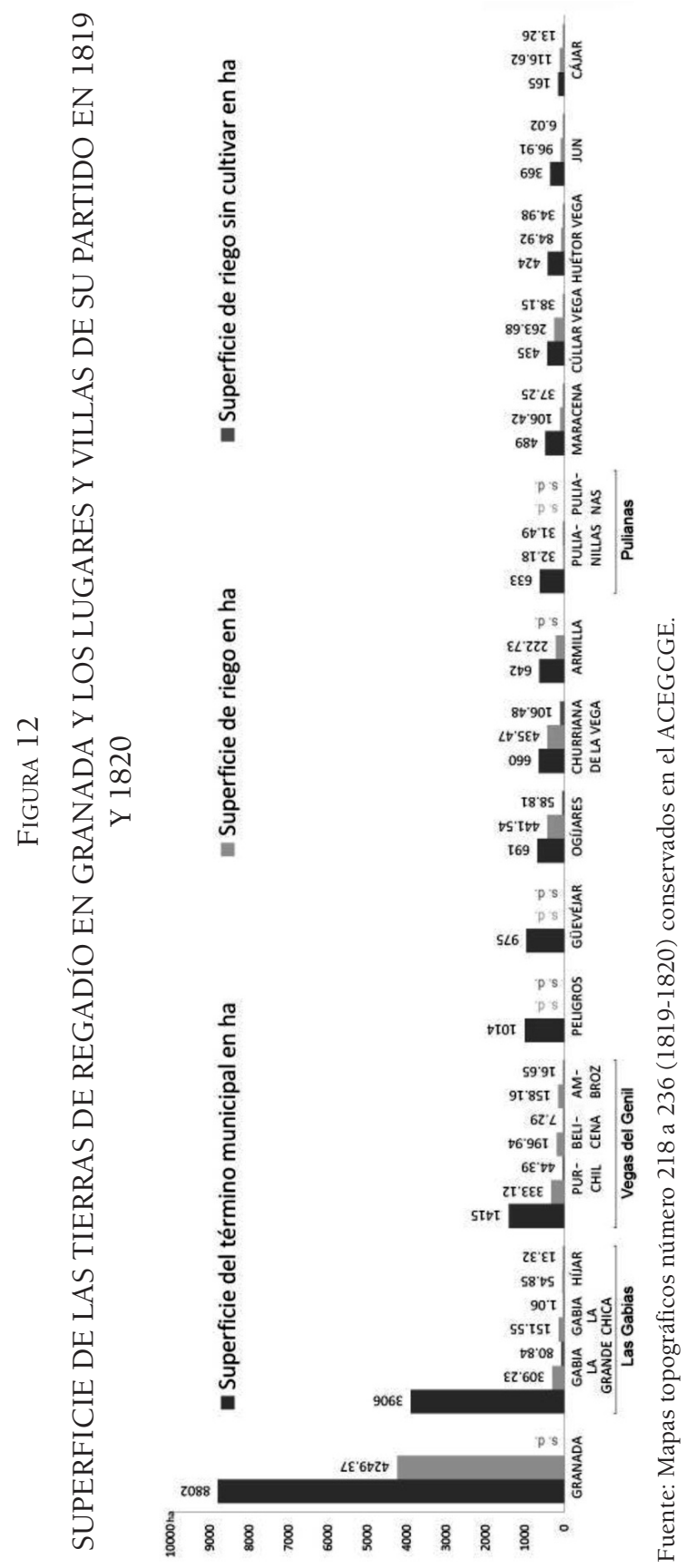

Estudios Geográficos, Vol. LXXVII, 280, pp. 155-190, enero-junio 2016

ISSN: 0014-1496, eISSN: 1988-8546, doi: 10.3989/estgeogr.201606 


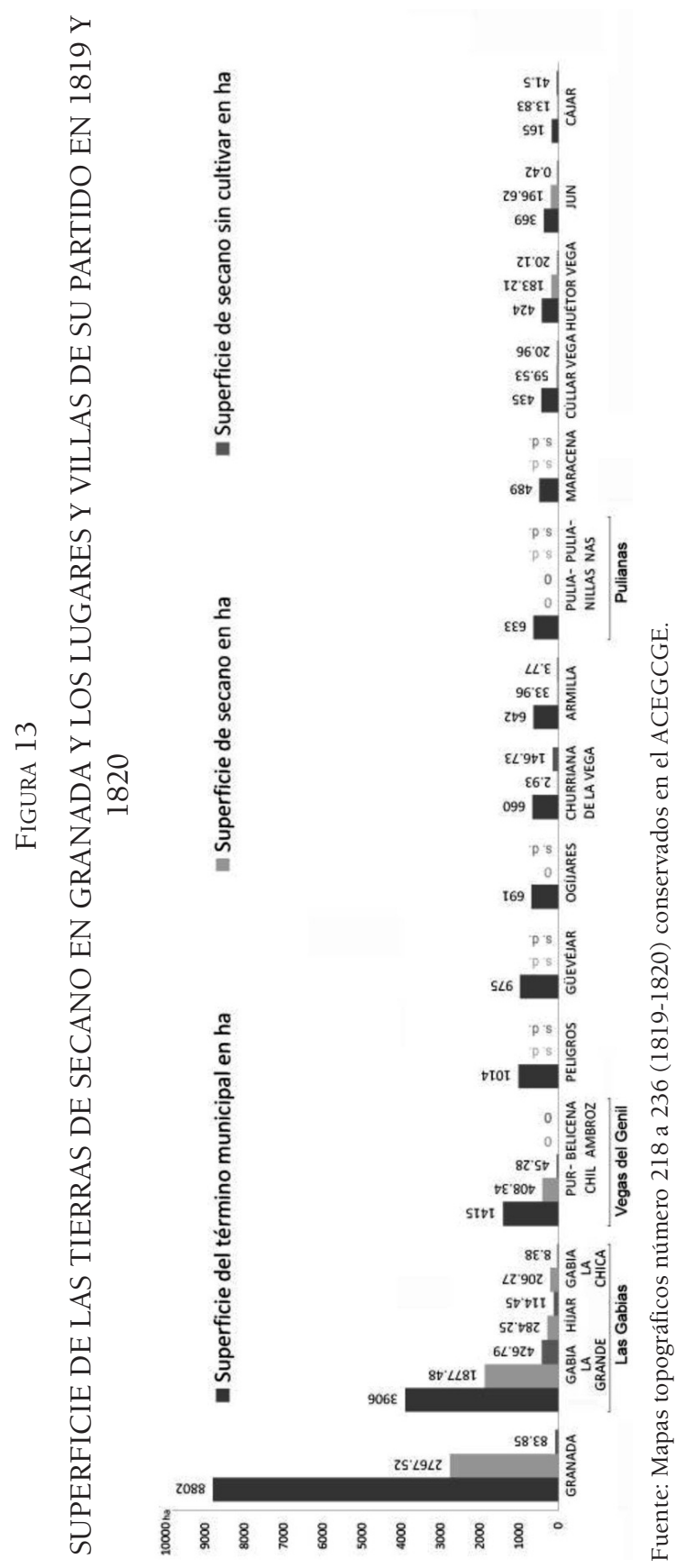

Estudios Geográficos, Vol. LXXVII, 280, pp. 155-190, enero-junio 2016 ISSN: 0014-1496, eISSN: 1988-8546, doi: 10.3989/estgeogr.201606 
El olivar presenta una proporción muy elevada en Maracena, donde la superficie destinada a este cultivo (reflejada en el mapa en marjales, por lo que debe de corresponder a regadío) es similar a la del término municipal de Granada (donde sí se especifica olivar de regadío y de secano), siendo el territorio granadino del orden de 20 veces superior al de Maracena (figura 14).

\section{FIGURA 14}

SUPERFICIE DE LAS TIERRAS DEDICADAS AL OLIVAR Y A LA VIÑA EN

GRANADA Y ALGUNOS LUGARES Y VILLAS DE SU PARTIDO EN 1819 Y 1820

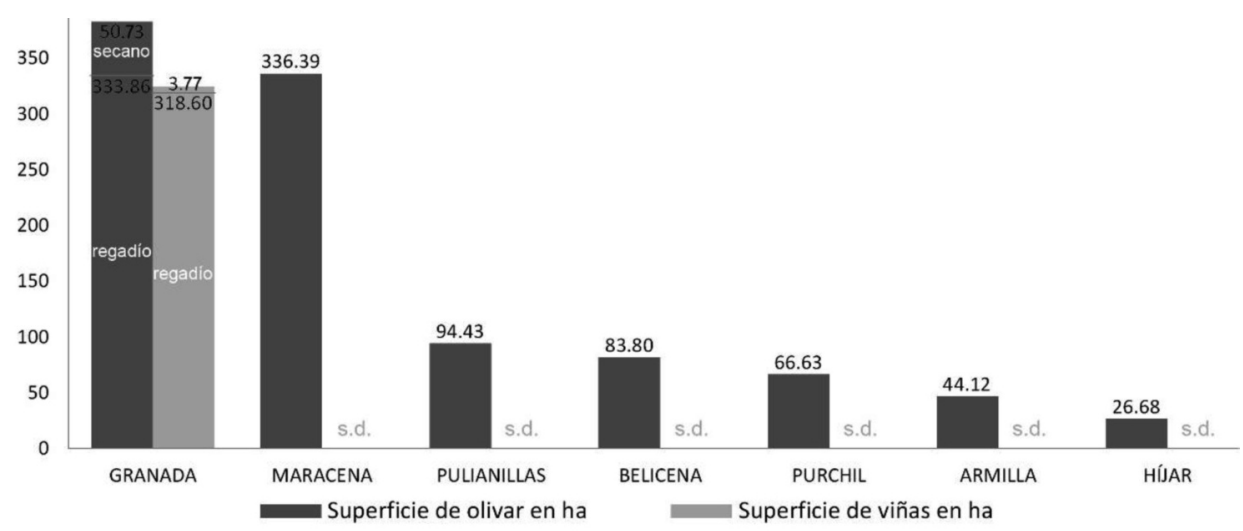

Fuente: Mapas topográficos número 218 a 236 (1819-1820) conservados en el ACEGCGE.

Este cultivo ha estado presente en la Vega de Granada al menos desde época romana, tal y como ha atestiguado la arqueología. El olivar que aparece reflejado en los libros de apeo que se realizaron tras la expulsión de los moriscos en la década de 1570 presenta siempre una proporción limitada, en muchos casos no superior al del cultivo de los morales y moredas que sostenían la industria de la seda. A menudo era utilizado en los bancales de tradición medieval para mantener el terreno y dar sombra a las herbáceas. Habría comenzado a ser plantado más intensivamente en el siglo xviII, tal y como muestran los libros del Catastro de la Ensenada, que siguen manifestando la existencia de este cultivo en tierras de regadío, como los 2.400 olivos nuevos en el término de Gabia la Chica o los 5.500 de Belicena. En Granada ocupaban 176,12 ha en 1752, estando plantados en su inmensa mayoría «dispersos y sin orden» y en otras 144,31 ha compartían espacio con morales y frutales (Do- 
mínguez Ortiz, 1990: 45-45). Seguiría incrementándose en el siglo XIX, apareciendo representado en los mapas de 1819 y 1820 con amplias zonas señaladas con una retícula de olivos. Habría alcanzado sus límites actuales hacia 1930, de modo que más recientemente existen unas 12.000 ha de olivar de secano en la Vega, estando escasamente representado en las parcelas de regadío (Ocaña Ocaña, 1974: 215).

El viñedo sólo se consignó en el caso de Granada, con una superficie cercana a la del olivar (figura 14), constatándose la existencia de tres calidades en este cultivo para el caso del regadío. Aunque había viñas en época andalusí, la plantación de mayores extensiones se produjo tras la conquista de Granada. En el Catastro de la Ensenada se muestran grandes superficies irrigadas destinadas a las cepas en Pulianas, Las Gabias, Cúllar Vega, Belicena y Pulianillas. El cultivo alcanzó una importancia mayor en el siglo XIX al sobrevenir la ruina del viñedo francés y como consecuencia de la mejora de las comunicaciones, siendo enviados los caldos de mejor calidad a Inglaterra. Aunque hoy quedan pocos rastros de esta plantación, la Vega en el siglo XIX podría considerarse como una zona vinícola, como lo demuestra el mapa de 1819 de Granada, donde fueron consignadas 318,60 ha de viña de regadío y 3,77 ha de secano, una superficie algo inferior a las 350,18 ha indicadas en el Catastro de la Ensenada (Domínguez Ortiz, 1990: 45-45). Hacia 1870 el viñedo ascendía a unas 2.000-3.000 ha entre los partidos de Granada y Santa Fe (Veu Peralta, 1885; Morell Terry, 1888: 73). Este cultivo sufrió un importante declive a raíz de la crisis de la filoxera que alcanzó la Vega de Granada tras verse infectadas las Alpujarras en 1883. Al igual que pasó con la desaparición de moredas y morales en el siglo XVIII, a finales del siglo xx su producción era ya casi anecdótica en relación a otros cultivos, apenas unas 350 ha dispersas en toda la Vega, a favor de las tierras de sembradura, o bien, sobre todo en el borde norte, por nuevos plantíos de olivar (Ocaña Ocaña, 1974: 215-220).

\section{LA PRODUCCIÓN AGRÍCOLA EN ESPAÑA EN LA SEGUNDA DÉCADA DEL SIGLO XIX}

En los dos primeros decenios del siglo XIX se produjo una fase depresiva de la agricultura española en general, hecho que contrasta con el crecimiento que ésta había experimentado en el siglo XVIII, si bien ya se había producido un estancamiento en las dos últimas décadas de esta centuria. Esto queda puesto de manifiesto en la serie de «censos, estados y evaluaciones» relativos a estas cosechas que se han conservado para los años de 1791, 1797, 1799, 1803, 1809 y 1818. Una memoria de 1820 presentada a las Cortes del Trienio Constitucional 
indicaba que, en 1799 se habían recogido 60 millones de fanegas de trigo, centeno y cebada, frente a los 51 de 1818 (Canga Argüelles, 1833-1834, vol. I: 359). Los datos del Obispado de Granada también muestran que el trigo diezmado en 1811-1813 fue un 40\% inferior al de 1790-1794 (Garzón Pareja, 1974), hecho que resultó ser mucho más acusado en otras zonas limítrofes como Málaga.

Los mapas y estadísticas productivas del partido de Granada dirigidos por Francisco Dalmau se enmarcan en el momento final de esta crisis de la producción agrícola. Su elaboración obedece a las primeras tentativas para analizar pormenorizadamente el potencial agrícola y productivo de las regiones españolas. Entre 1817 y 1819, Fernando VII habría permitido exportar el grano y en 1820 se produjeron cambios en la política arancelaria que posibilitarían la recuperación definitiva a partir de 1830, lo que queda reflejado en el saldo positivo del comercio exterior de harinas y la tendencia al alza de los precios (Garrabou Segura, 1974: 208-209 y 223-224; Garrabou Segura, 1975: 182-183). A este hecho se sumó que la extensión de la superficie nacional destinada al cereal aumentó en la primera mitad del siglo xIx en torno a un 50\%.

Además, dado el potencial agrícola de Andalucía, el progreso fue parejo en los otros dos subsectores básicos que constituían la trilogía mediterránea. Sin duda fue el cultivo del olivar el que desde el siglo xviI experimentó un avance más significativo, sobre todo en las provincias de Jaén y Granada. A finales de esta centuria la producción de aceite andaluz representaba más de la tercera parte del total nacional según el Censo de la riqueza territorial e industrial de España de 1797. La crisis general de la agricultura de las dos primeras décadas del siglo XIX también afectó al olivar (Álvarez Pantoja, 1970), si bien la recuperación posterior estuvo acompañada por la introducción de numerosos plantíos en las faldas de las sierras en las provincias del interior. La Guía mercantil de España de 1829 y la Guía del Ministerio de la Gobernación del Reino de 1836 muestran que la mitad de las fábricas jaboneras, molinos aceiteros, prensas y almazaras de toda España se encontraban en Andalucía, donde Granada ya era la segunda provincia en importancia con 49 instalaciones jaboneras y 55 aceiteras, superadas solamente por Jaén, desbancando a las tradicionales regiones sevillanas y cordobesas que desde época romana habían destacado por la producción y exportación de aceite.

Uno de los factores que determinó el progreso del sector olivarero y sus industrias fue su alta rentabilidad, mayor que la de los cereales, así como la coyuntura favorable que se dio en la primera mitad del siglo xIX para la exportación de aceite al mercado europeo y en especial al británico, lo que multiplicó por 100 la producción a escala nacional. Este hecho queda patente en los registros del mapa de 1819, donde se constata la gran cantidad de esta- 
cas y nuevos plantones de este cultivo en algunos pagos del ruedo granadino. Al tradicional consumo dietético que ya se daba, se sumó la gran demanda que se produjo en los primeros momentos de la revolución industrial hasta la obtención masiva de los aceites de origen fósil. Con el crecimiento continuo del olivar hasta el tercer cuarto del siglo XIx, Andalucía llegó a copar más de las 3/4 partes de la exportación total española de este producto (Abela y Sainz de Andino, 1879: 695), lo que generó una importante fuente de ingresos para los propietarios latifundistas.

Aunque, según ha quedado expresado,la vid estaba también representada en la Vega de Granada, donde realmente se desarrollaría sobremanera serían en las provincias litorales andaluzas, sobre todo en Málaga y Cádiz, cuya producción vinícola a finales del siglo XVIII correspondía al 13,65\% del total nacional y a casi la mitad andaluza (Yoshiyuki Kondo, 1990: 20-25 y 72-77). A ello se sumaba la facilidad de la exportación marítima hacia la creciente demanda que se produjo en el norte de Europa y a la política cada vez más liberalizada que se puso en vigor para favorecer su exportación.

\section{CONCLUSIONES}

Los mapas realizados por Francisco Dalmau constituyen un eslabón entre los documentos cartográficos elaborados en la Ilustración, ornados con cartelas exuberantes y otros artificios gráficos, y los avances científicos y técnicos desarrollados a raíz de la Revolución Industrial. En el siglo XVIII las Monarquías Ilustradas potenciaron la realización de mapas de sus territorios con una visión militar, pero también para promover la explotación de las fuentes de riqueza del país. Surgieron de este modo diversas cartografías donde se representaba la creciente información gráfica y estadística que se recopilaba en las relaciones geográficas, censos y catastros (Nadal y Urteaga, 1990), como el promovido por el Marqués de la Ensenada (1749-1759). Los mapas topográficos de Francisco Dalmau recogieron lo más avanzado de esta tradición, grafiando plásticamente los territorios municipales de Granada y los lugares y villas de su partido. Aunque los mismos tuvieron una función civil, adaptaron los novedosos criterios de representación que se habían plasmado en algunas de las cartografías realizadas por los ingenieros militares desde mediados del siglo XVIII. Esto podría explicar el hecho de que todos los ejemplares de estos mapas se hayan conservado en el Archivo Cartográfico y de Estudios Geográficos del Centro Geográfico del Ejército. El Cuerpo de Estado Mayor español había sido creado en 1810, aunque no sería consolidado hasta 1838. Cuatro 
años más tarde se aprobaba el Depósito de Guerra, que entre otras funciones tenía la de reunir, examinar y coleccionar documentos clave de índole geográfica y topográfica o de historia y estadística militar. Por ello debió de adquirir todos estos mapas dirigidos por Francisco Dalmau años atrás.

Si el mapa de 1819 es un documento gráfico de excepcional valía para conocer la configuración del término municipal granadino, los planos realizados un año más tarde representan la continuación del trabajo cartográfico realizado por Francisco Dalmau. En ellos quedaron reflejados los elementos vertebradores de los términos municipales de estas poblaciones, teniendo que esperar a los planos territoriales elaborados en 1868 y 1887 por los ingenieros militares del Cuerpo de Estado Mayor para tener documentos cartográficos más precisos del entorno territorial granadino.

La labor cartográfica desempeñada por este autor gracias a sus sobresalientes conocimientos técnicos, científicos, históricos y artísticos y a su nombramiento como director de la Estadística de la Provincia de Granada, ha de ser reconocida como pionera en el campo del catastro territorial en España. Por ello, estos mapas topográficos no sólo representan la culminación de la experiencia vital de Francisco Dalmau, sino que al mismo tiempo constituyen un precedente excepcional de la cartografía y la estadística parcelaria española.

Aún a mediados del siglo XIX, el país no disponía en su conjunto de planimetría parcelaria ni de un proyecto de catastro general. Por aquel entonces los principales países de Europa occidental ya contaban con detallada cartografía catastral, con mapas topográficos en los que se incluían los usos del suelo. Francia había finalizado en 1850 el catastro parcelario iniciado por Napoleón en 1808. Baviera incluso había adelantado estos trabajos a 1801, aunque no los vería concluidos hasta 1867. Holanda finalizaba en 1831 el suyo propio, comenzado en 1814, Inglaterra terminaba en 1854 un conjunto de planos parcelarios iniciados en 1836 y la montañosa Austria acababa en 1861 su cartografía comenzada en 1817 (Muro, Nadal y Urteaga, 1996: 106-110). Incluso el Reino de Nápoles había realizado el denominado Catastro Borbónico di Sicilia entre 1837 y 1853 (Caruso y Nobili, 2001: 35-81). La iniciativa de Francisco Dalmau desarrollada en el marco de la Estadística del Reino promulgada por Marín de Garay, se puede equipar a las cartografías parcelarias realizadas en dichos estados europeos en la primera mitad del siglo XIX.

Los mapas topográficos de 1819 y 1820 son unos documentos gráficos de excepcional valía para conocer la configuración del término municipal de Granada y de otros 18 lugares y villas colindantes. El estudio de los elementos conservados en estas cartografías permite analizar la organización espacial del entorno de Granada con anterioridad a las profundas alteraciones ocurridas 
desde la segunda mitad del siglo xx. Por su rigor, minuciosidad y calidad gráfica constituyen también una importante fuente documental para analizar la pervivencia de estructuras e infraestructuras de época medieval fosilizadas aún en el territorio, tales como la distribución parcelaria en pagos agrícolas y la red de regadío de los mismos.

En las últimas décadas se ha producido en la Vega la ruptura de un equilibrio paisajístico que había perdurado al menos desde época andalusí, que ha supuesto el consumo del espacio cultivado para su reordenación territorial. La progresiva intensificación de la influencia de la ciudad de Granada ha devenido en la configuración de un área suburbana en torno a la capital que ha transformado el modelo territorial, con la pérdida de la monofuncionalidad agraria de la periferia, dando paso a una multiplicidad de usos del territorio. Estas alteraciones han sido debidas al enorme crecimiento físico y demográfico de Granada y de los municipios de su entorno, provocando el cambio de los usos del suelo, que han pasado del carácter agrario al residencial, industrial y/o de equipamientos, afectando incluso a las tierras de regadío más productivas y fértiles. Se ha generado así un espacio urbano discontinuo separado por intersticios de espacios rurales (Menor Toribio, 2000), frente a la dualidad campo-ciudad que todavía aparece reflejada en los mapas topográficos de 1819 y 1820.

\section{REFERENCIAS BIBLIOGRÁFICAS}

Abela y Sainz de Andino, E. (1879): "Producción de olivares y comercio de sus frutos en España", Gaceta Agricola del Ministerio de Fomento, 12, pp. 611-617 y 690-702.

Álvarez Pantoja, M. J. (1970): Aspectos económicos de la Sevilla Fernandina (18001833), tomo I, Sevilla, Diputación Provincial de Sevilla.

Barrios Aguilera, M. (1987): "Táfiar Zufla, un pago morisco del ruedo de la ciudad de Granada (según el apeo de Loaysa de 1574)", en Homenaje al Prof. Darío Cabanelas Rodríguez, O.F.M., con motivo de su LXX aniversario, Granada, Editorial Universidad de Granada.

Barrios Rozúa, J. M. (2013): Granada napoleónica, Granada, Editorial Universidad de Granada.

Bringas Gutiérrez, M. Á. (1994): "Los cuadernos generales de la riqueza (1818-1820): La localización de una fuente histórica en España", Noticiario de Historia Agraria, 7, pp. 155-179.

Bringas Gutiérrez, M. Á. (2003): "Un catastro poco conocido: el apeo y valuación general de Martín de Garay, 1818-1820", Catastro, abril, pp. 143-157.

Calatrava Escobar, J. y Ruiz Morales, M. (2005): Los planos de Granada 1500-1908. Cartografía urbana e imagen de la ciudad, Granada, Diputación de Granada. 
Camarero Bullón, C. (2002): "El Catastro de la ensenada, 1749-1759: diez años de intenso trabajo y 80.000 volúmenes manuscritos", Catastro, Diciembre, pp. 61-88.

Camarero Bullón, C., Ferrer Rodríguez, A. y Nieto Calmaestra, J. A. (2012): "La cartografía parcelaria urbana de Granada (1867-1868): levantamientos topográfico-parcelarios de la Junta General de Estadística”, Catastro, Abril, pp. 27-58.

Canga Argüelles, J. (1833-1834): Diccionario de Hacienda con aplicación a España, Madrid, Imprenta de M. Calero.

Caruso, E. y Nobili, A. (dir.) (2001): Le Mappe del "Catastro Borbonico" di Sicilia. Territori comunali e centri urbani nell'archivio cartográfico Mortillaro di Villarena (1837-1853), Palermo, Regiono Siciliana, Assesorato dei Beni Culturali ed Ambientali e della Pubblica Istruzione.

Clemente Rubio, S. de R. (1804-1809): Viaje a Andalucía. "Historia natural del reino de Granada" (1804-1809), edición, transcripción, estudio e índices de Antonio Gil Albarracín (2002), Almería-Barcelona, Editorial Griselda Bonet Girabert.

Domínguez Ortiz, A. (1990): Granada, 1752, según las respuestas generales del Catastro de la Ensenada, Madrid, Centro de Gestión Catastral y Cooperación Tributaria, Tabapress.

Gámiz Gordo, A. (2008): Alhambra. Imágenes de ciudad y paisaje (hasta 1800), Granada, El Legado Andalusí y Patronato de la Alhambra y Generalife.

García-Pulido, L. J. (2013): "Una precisa y artística representación gráfica del territorio granadino: el Mapa topográfico de la ciudad de Granada y su término de Francisco Dalmau (1819)", Cuadernos de Arte de la Universidad de Granada, 44, pp. 171-198.

Garzón Pareja, M. (1974): Diezmo y tributos del clero de Granada, Granada, Archivo de la Real Chancillería.

Garrabou Segura, R. (1974): "Las transformaciones agrarias durante los siglos XIX y Xx", en J. N. Gabriel Tortella (coord.), Agricultura, comercio colonial y crecimiento económico en la España contemporánea: Actas del Primer Coloquio de Historia Económica de España, Barcelona, Editorial Ariel, pp. 206-229.

Garrabou Segura, R. (1975): "La crisis agrària espanyola de finals del segle xIx: una etapa del desenvolupament del capitalisme", Recerques, 3, pp. 163-216.

Jiménez Serrano, B. y Serrano Gutiérrez, J. (2004): El Catastro del Marqués de la Ensenada en el antiguo Reino de Granada, Granada, Consejería de Cultura de la Junta de Andalucía.

Juste Ocaña, J. (2008): "Útil y sutil: Francisco Dalmau y el Plano Topográfico de Granada de 1796", en http://citywiki.ugr.es/wiki/Archivo:Cabecera-Dalmau-J-J.gif (Fecha de consulta: 24.11.2014).

Lévi-Provençal, É. (1938): La Péninsule Ibérique au Moyen-Age d'après le Kitab ar-rawd al-mi'tar fi habar al-aktar d'Ibn 'Abd al Mun'im al-Himyari, Leiden, E. J. Brill, S.A.

Lorenzo Rojas, J. F. (2009): "Diccionario Geográfico de Tomás López. Las encuestas y su edición”, en J. M. García Martín, y V. Gaviño Rodríguez, (coords.), Las ideas y realidades lingüísticas en los siglos XVIII y XIX, Cádiz, Universidad de Cádiz, pp. 415-426.

Madoz, P. (1845-50): Diccionario geográfico-estadístico-histórico de España y sus posesiones de ultramar, Madrid, Imprenta del Diccionario, 16 vols. 
Menor Toribio, J. (2000): La Vega de Granada: transformaciones agrarias recientes en un espacio periurbano, Granada, Universidad de Granada.

Morell Terry, L. (1888): Estudio sobre las causas de la decadencia de la agricultura en la provincia de Granada y medios de regenerarla, Granada, imprenta de Indalecio Ventura Sabatell.

Muro, J. I., Nadal, F. y Urteaga, L. (1996): Geografía, estadística y catastro en España, 1856-1870, Barcelona, Ediciones del Serbal.

Muro, J. I., Urteaga, L. y Nadal, F. (2005): "Los trabajos cartográficos y catastrales de Llorenç Presas i Puig (1811-1875)", Treballs de la Societat Catalana de Geografia, 59 , pp. 7-39.

Nadal, F., Muro, J. I. y Urteaga, L. (2003): "Cartografia parcel-lària i estadística territorial a la província de Barcelona (1845-1895)", Revista de Geografia, segunda época, 2, pp. 37-60.

Nadal, F. y Urteaga, L. (1990): "Cartografía y Estado. Los mapas topográficos nacionales y la estadística en el siglo XIX", Geocrítica, 88, en http://www.ub.edu/geocrit /geo88.htm (Fecha de consulta: 24.11.2014).

Nadal, F., Urteaga, L. y Muro, J. I. (2006): El territori dels geòmetres. Cartografia parcellària dels municipis de la provincia de Barcelona (1845-1895), Barcelona, Institut d'Edicions de la Diputació de Barcelona.

Ocaña Ocaña, Ma . C. (1974): La vega de Granada: estudio geográfico, Granada, Instituto de Geografía Aplicada del Patronato "Alonso de Herrera" del CSIC/Caja de Ahorros de Granada.

Puig Pla, C. (2000): "Desarrollo y difusión de la construcción de máquinas e instrumentos científicos: el caso de Barcelona, siglos XVIII-XIX", Scripta Nova: Revista electrónica de geografía y ciencias sociales, 4.

Puig Pla, C. (2006): "Física, tècnica i Il-lustració a Catalunya. La cultura de la utilitat: assimilar, divulgar, aprofitar", tesis doctoral del Departament de Física, Facultad de Ciències, Universidad Autònoma de Barcelona, vol. I.

Quirós Linares, F. (2009): Las ciudades españolas en el siglo XIX. Francisco Coello, Altas de España y sus Posesiones de Ultramar (Planos de núcleos urbanos), 1847-1876, Gijón, Trea.

Reguera Rodríguez, A. T. (1998): Geografía del Estado: los marcos institucionales de la ordenación del territorio en la España contemporánea (1800-1940), León, Universidad de León.

Ruiz Morales, M. (1996): "El Catastro Topográfico Parcelario del Término Municipal de Granada (1946-1950)", tesis doctoral de la Universidad de Granada.

Santos Pérez, L. J. (2012): "Los fondos de cartografía histórica de la Dirección General del Catastro", Catastro, Diciembre, pp. 41-64.

Urteaga, L. (2011): "El profesorado de la Escuela del Catastro (1859-1869)", Catastro, Abril, pp. 29-53.

Veu Peralta, B. (1885): Estudio sobre el cambio y mejoramiento del cultivo en la Vega y demás territorios de la provincia de Granada, Granada, imprenta de Indalecio Ventura Sabatell. 
Viñes Millet, C. (2004): Granada ante la invasión francesa, Granada, Ayuntamiento de Granada.

Yoshiyuki Kondo, A. (1990): La agricultura española del siglo XIX, Madrid, Ministerio de Agricultura, Pesca y Alimentación.

Fecha de recepción: 27 de noviembre de 2014.

Fecha de aceptación: 17 de julio de 2015.

\section{RESUMEN}

En 1819 se elaboró con notable precisión y calidad gráfica el Mapa topográfico de la ciudad de Granada y su término, obra pionera en el ámbito de los planos catastrales parcelarios españoles. Su autor fue Francisco Dalmau (1766-1824), matemático ilustrado que acaparó numerosos títulos, culminados con el de director de la Estadística de la Provincia de Granada. Un año más tarde dirigió la elaboración de 18 mapas más, correspondientes a los términos municipales de los lugares y villas del partido granadino. Con esta iniciativa se adelantaría en varias décadas a los trabajos de similares características realizados en otras poblaciones españolas. En este artículo se ofrece una completa visión del uso del suelo agrario en el entorno de la capital granadina a partir del análisis conjunto de los datos geográficos contenidos en estas cartografías que, pese a que fueron promovidas fuera del ámbito militar, se han conservado en el Centro Geográfico del Ejército.

PALABRAS ClAVE: cartografía histórica; catastro parcelario; geografía agraria; periferia urbana; representación gráfica; ciudad de Granada.

\section{ABSTRACT}

The Topographic map of the city of Granada and its municipal district was accomplished in 1819 with accuracy and graphical quality as a pioneering work in the area of the land registries maps in Spain. It was conducted by Francisco Dalmau (1766-1824), illustrate mathematic who accomplished numerous titles ending with Headmaster of the Statistics of the Province of Granada. One year later he directed 18 maps more, corresponding to some towns and villages in Granada district. These documents are previous in some decades to other similar works done in Spanish cities. This article gives a general layout of the agrarian land of the surroundings of Granada from the global analysis of these cartographic documents and their geographic data that, in spite of have been promoted out of the military scope, are preserved in the Army's Geographic Centre.

KEY WORDS: historical cartography; land registries maps; agricultural geography; urban periphery; graphical representation; Granada city. 